\title{
Displacement response to axial cycling of piles driven in sand
}

Siya P. Rimoy MSc, DIC

PhD research student in geotechnics, Department of Civil and Environmental Engineering, Imperial College London, UK

Richard J. Jardine FREng, FICE, FCGI

Professor in Geomechanics, Dean of Engineering, Department of Civil and Environmental Engineering, Imperial College London, UK
Jamie R. Standing MSc, PhD, DIC, MICE

Senior Lecturer in Geotechnics, Department of Civil and Environmental Engineering, Imperial College London, UK

A review of the load applied to multi-pile offshore wind turbine foundations is presented, from which the need to consider the response to axial cyclic loading is emphasised. The paucity of available data on field tests on driven piles in sand is noted. A comprehensive data set of multiple axial cyclic and static tests conducted on seven industrial-scale steel pipe-piles at a marine sand site in Dunkerque, France, is re-examined in this paper. The effects of cycling on axial capacity are interpreted by reference to stable, metastable or unstable zones defined in a normalised cyclic stability interaction diagram. A detailed analysis is made of the load-displacement and stiffness response associated with each mode of cycling. It is shown that in all cases the piles' cyclic stiffnesses show only minor changes until cyclic failure is approached. The patterns of permanent cyclic strain accumulation are sensitive to the applied mean and cyclic loading levels. Whereas displacements accumulate rapidly over just a few cycles in the unstable zone, extended cycling in the stable zone leads to minimal accumulated displacements and constant transient cyclic displacements.

Notation
$D$
$d$
$G_{\text {compression }}$
$G_{\text {extension }}$
$G_{\mathrm{S}}$
$I_{\mathrm{D}}$
$K_{0}$
$k_{\mathrm{l}}$
$k_{N=1}$
$k_{\text {Ref }}$
$k_{\mathrm{u}}$
$Q_{\mathrm{cla}}$
$Q_{\mathrm{T}}$
$Q_{\text {mean }}$
$Q_{\text {max }}$
$N_{\mathrm{f}}$

$Q_{\text {mac }}$

permanent accumulated cyclic displacement pile external diameter transient cyclic displacement shear stiffness in triaxial compression shear stiffness in triaxial extension specific gravity density index coefficient of earth pressure at rest load-displacement axial cyclic stiffness during loading

load-displacement axial cyclic stiffness at first cycle

initial maximum reference load-displacement secant stiffness

load-displacement axial cyclic stiffness during unloading

pile embedded length

number of cycles

number of cycles to failure in pile axial cyclic loading

axial cyclic load amplitude maximum axial cyclic load mean axial cyclic load minimum axial cyclic load first axial load step applied pile tension capacity CPT tip resistance mean centreline roughness stable axial cyclic loading condition shear force applied to pile shaft pipe-pile wall thickness local settlement inducing shear force $\mathrm{T}$ saturated bulk unit weight pile-head axial load increment pile-head settlement or uplift displacement increment

$\delta_{\mathrm{cv}}^{\prime} \quad$ angle of constant-volume interface shearing resistance angle of peak interface shearing resistance shear strain invariant effective normal stress angle of critical state shearing resistance angle of peak shearing resistance

\section{Introduction}

The axial cyclic response of driven-pile foundations can be important in the design of conventional offshore oil and gas platforms and onshore facilities such as towers and pylons (Jardine, 1991; Poulos, 1988). It may be still more critical in offshore wind turbines that rely on tripods or jacket structures. Turbines commissioned in relatively shallow waters $(<30 \mathrm{~m})$ are currently mostly founded on monopiles $(75 \%)$ or gravity-based structures (20\%) (Gavin et al., 2011), whose axial response is often not a significant concern. With deeper water sites, jacket and tripod structures founded on open-ended driven pipe-piles become more attractive (e.g. Seidel, 2007). The lateral and moment loads imposed by wind or wave action can be large in 
comparison with self-weights, leading to multiple modes of axial and lateral cyclic loading acting on the foundation piles. While lateral loading model test data have been reported for monopiles (Leblanc et al., 2010), less guidance is available regarding fullscale displacement accumulation and stiffness responses under axial cycling.

Jardine et al. (2012) reviewed the potential effects of cyclic loading on offshore piles, and considered how these may be addressed in practical design. They outlined the indicative ranges for cyclic loading components that might apply to the range of multiple pile structures listed in Table 1, noting that the loads vary with platform weight, water depth, metocean environment, and structural form. In these examples the worst storm events (100year return period for oil/gas and 50-year return period for wind energy) set the design-critical conditions. Following the cyclic loading convention in Figure 1 , the average ratio of $Q_{\text {cyclic }} / Q_{\text {mean }}$ on the windward side is around 7.8, and that on the leeward is just above $1 \cdot 0$, the limiting value for the pile loads to become tensile. The maximum compressive loads developed on the leeward side, $Q_{\max }=Q_{\text {mean }}+Q_{\text {cyclic }}$, usually constitute the critical conventional design case, although this may alter after accounting for cyclic loading effects. Cyclic effects may be more marked for the tensile load cases, but there are broad spreads of ratios between both wind

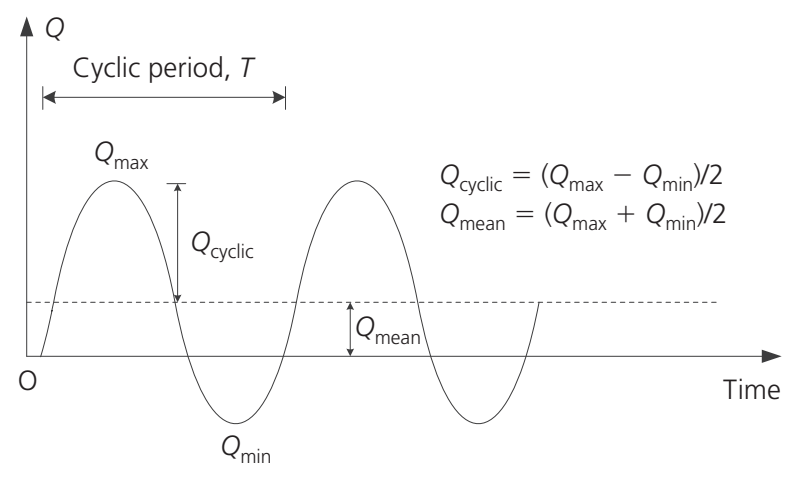

Figure 1. Load-controlled axial cycling illustrated (Tsuha et al., 2012) turbines and conventional oil and gas jackets. For example, tension is more critical for Case G, of a tripod wind turbine founded in sand, and it could also be with some wind turbine jacket structures in deeper water.

Jardine et al. (2012) summarised data from field investigations involving the response to axial cyclic loading of steel piles; they noted 14 case histories in clay and only one in silica sands at Dunkerque, France, reported by Jardine and Standing (2000, 2012). As described by Merritt et al. (2012), cyclic pile behaviour under the first few hundred cycles represents the most critical condition to be satisfied in design, and the Jardine and Standing (2000) tests represent the only field study of which the current authors are aware that investigates such behaviour up to $1000 \mathrm{cy}$ cles. More extended tests on sands have been performed in laboratory centrifuges (Puech et al., 2012) and calibration chambers (Tsuha et al., 2012), and are planned for a secondary campaign of full-scale tests at Dunkerque (Puech et al., 2012).

A range of analytical techniques that can be applied in axial cyclic design were set out by Jardine et al. (2012), and Merritt et al. (2012) described a practical application to a wind farm founded in sand. Both papers emphasise the use of interactive cyclic stability diagrams to guide the assessment of global axial cyclic load capacity degradation for driven piles, as advocated previously by Karlsrud et al. (1986), Poulos (1988) and Jardine and Standing (2000). These cyclic stability diagrams consider the interaction effects of cyclic and mean loads (normalised by static capacity before cycling) and the number of cycles applied. Such interaction diagrams may be zoned to identify a cyclically stable (S) region where there is no reduction of load capacity after $N$ cycles, a metastable (MS) area where some reduction of load capacity occurs after $N$ cycles, and an unstable (US) zone where cyclic failure develops within a small specified number of cycles. Tsuha et al. (2012) proposed quantitative definitions for the three zones when reporting model pile tests in silica sand. They also provided insights into the interface shear behaviour and sand mass response to cyclic pile loading. Jardine and Standing (2012) applied a similar scheme in interpretation of their field tests at Dunkerque (Figure 2). Stable cyclic responses were associated

\begin{tabular}{lccc}
\hline Jacket code, location and type & Water depth: $m$ & Leeward $Q_{\text {cyc }} / Q_{\text {mean }}$ & Windward $Q_{\text {cyc }} / Q_{\text {mean }}$ \\
\hline A West of Shetland, oil/gas & 140 & 0.36 & 6.69 \\
B China Sea, oil/gas & 36 & 0.60 & 3.00 \\
C China Sea, oil/gas & 49 & 3.18 & 4.68 \\
D North Sea, oil/gas & 70 & 0.72 & 2.47 \\
E North Sea, wind turbine jacket & 35 & 0.72 & 1.25 \\
F North Sea, wind turbine jacket & 50 & 1.13 & 35.00 \\
G North Sea, wind turbine tripods & $26-33$ & 0.88 & 1.66
\end{tabular}

Table 1. Indicative ranges for cyclic loading components; sites A to $\mathrm{F}$ predominantly clay, site $\mathrm{G}$ mainly sand (after Jardine et al., 2012) 


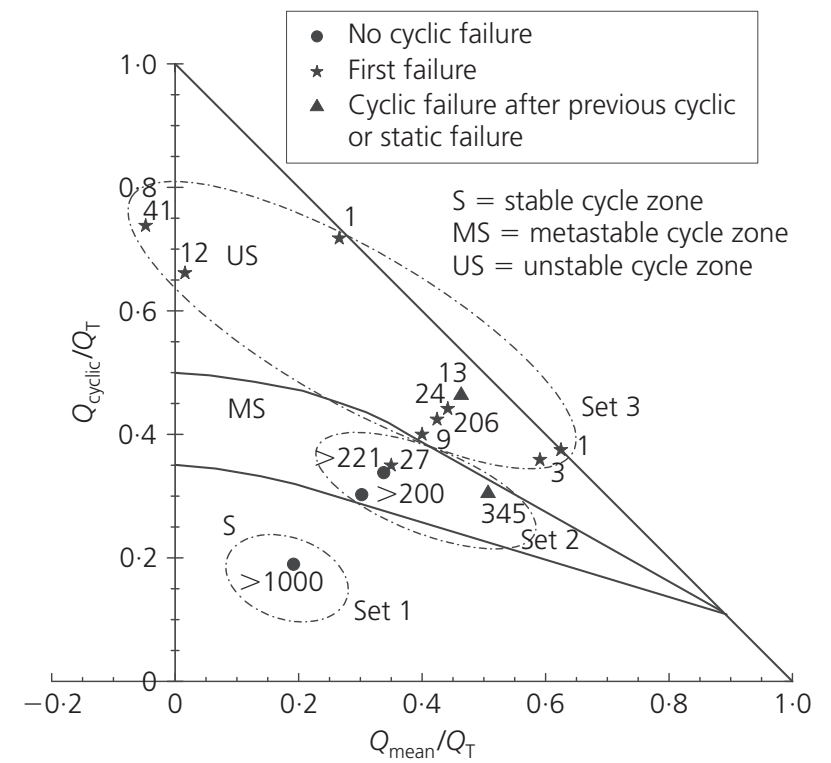

Figure 2. Axial cyclic interaction diagram for full-scale pile tests in Dunkerque silica marine sands (Jardine and Standing, 2012)

with low and stabilising accumulated displacements up to a relatively large number of cycles $(>1000)$, but behaviour was deemed unstable if large displacements accrued leading to cyclic failure within less than 100 cycles. The intermediate metastable response zone was characterised as showing permanent displacement trends that did not stabilise between 100 and 1000 cycles and resulted in either failure or degradation in axial capacity.

A first-stage screening process for axial cyclic design is described in Figure 3 by plotting on the Dunkerque cyclic interaction diagram (Jardine and Standing, 2012) the most critically loaded piles from the range of storm conditions on the platforms listed in Table 1. In this simplified treatment it is assumed that all the piles were designed to give working stress design (WSD) factors of safety (FoS) of 1.5 with respect to their most critical single ultimate limit state (ULS) storm load; higher factors were in fact adopted in several of the practical cases considered. For example, referring to case $\mathrm{A}$ in Table 1 and Figure 3, for $Q_{\max } / Q_{\mathrm{T}}=$ $\left(Q_{\text {mean }}+Q_{\text {cyc }}\right) / Q_{\mathrm{T}}=1 / 1.5$ and $Q_{\text {cyc }} / Q_{\text {mean }}=0.36, Q_{\text {mean }} / Q_{\mathrm{T}}=$ 0.49 and $Q_{\text {cyc }} / Q_{\mathrm{T}}=0 \cdot 18$. Jardine et al. (2012) noted that leeward compressive conditions dominated in cases A to $\mathrm{F}$, whereas tension was more critical in case G. Pile-end resistance and group action are not considered in this illustration, but should be addressed in practice. The illustrative cases shown in Figure 3 have ULS events that plot above the stable contour, so some damage could be expected for each installation if founded in deposits comparable to the Dunkerque medium-dense marine sand. Cases B, D, E, F and G show a progression of reducing proximity to the $N_{\mathrm{f}}=1000$ contour, and hence increasing potential of cycling loading degradation. Case $\mathrm{C}$ plots above the $N_{\mathrm{f}}=100$ contour, indicating a considerable potential impact on this structure's foundation performance. Cyclic loading can

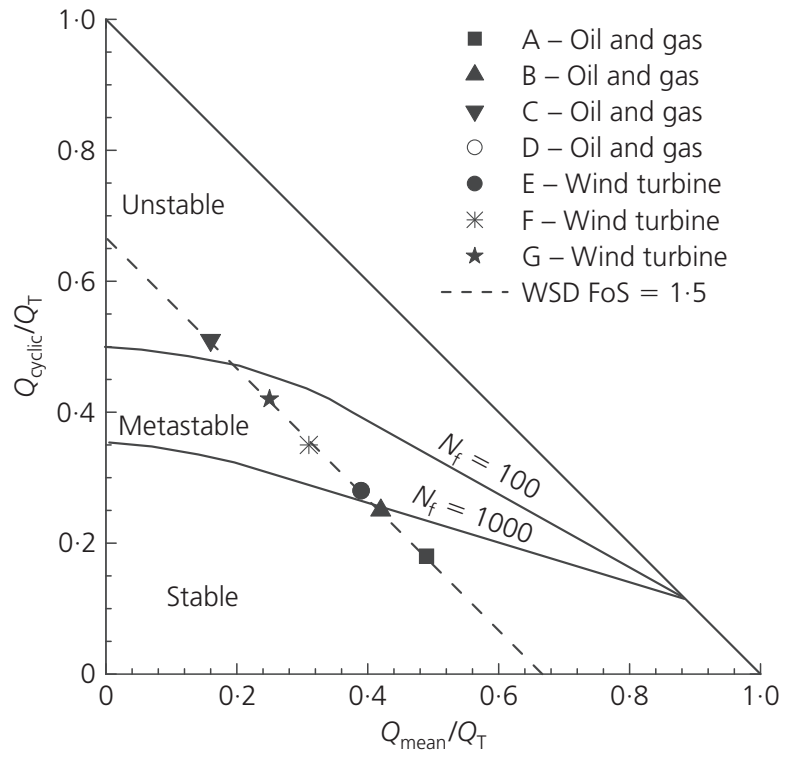

Figure 3. Illustration of potential cyclic effects for WSD FoS $=1.5$ design conditions compared with Dunkerque contours of stable, metastable and unstable condition in normalised cyclic interaction diagram

reduce the safety factor very significantly below 1.5 based on static shear strength, but by degrees that differ in each of the cases considered.

This paper focuses on further interpretation of the axial cycling experiments by Jardine and Standing $(2000,2012)$ at Dunkerque. It reviews the multiple cyclic loading tests performed that were interspersed with reference static tension capacity tests. The stiffness responses and cyclic displacements associated with each mode of cycling are examined, referring to the site-specific normalised cyclic interaction stability diagram.

\section{Scope of study}

Seven full-scale open-ended steel pipe-piles were installed as part of the GOPAL project (Parker et al., 1999). They were $457 \mathrm{~mm}$ in diameter, with $13.5 \mathrm{~mm}$ wall thickness (increased to $20 \mathrm{~mm}$ over the top $2.5 \mathrm{~m}$ ); six had embedded lengths around $19 \mathrm{~m}$, and one was driven to $10 \mathrm{~m}$. The piles were driven in the flat area close to Dunkerque Port Ouest Industrial Zone, where an earlier CLAROM driven-pile test programme had been conducted (Brucy et al., 1991). The site offers a relatively deep profile of dense Flandrian marine sands, similar to those at multiple North Sea offshore oil and gas platforms founded on open-ended driven steel pipe-piles (Thomas, 1990) and locations where wind turbine arrays are planned (e.g. Merritt et al., 2012). Six of the test piles (R1-R6) had been installed to provide reaction for the GOPAL project test piles $\mathrm{C} 1$ and JP1. The reaction loading applied either one or two significant tension load cycles to R1-R6 prior to the cyclic loading study, with maxima $<60 \%$ of the piles' ICP-05 design capacities (Jardine et al., 2005a). The piles' cyclic capacity trends 
have been reported by Jardine and Standing (2000, 2012), and Jardine et al. (2006) reported the piles' remarkable static tension capacity-time trends. Chow (1997) reported static and cyclic tests at the same site with the ICP (Imperial College pile) pile, which carries pore pressure sensors. The pore pressures showed a fully drained response. Although this is also expected at field scale with large piles in clean sands, partially drained behaviour might apply in lower-permeability deposits, as may be checked by inspecting piezocone data and applying consolidation analyses.

\section{Test site}

Jardine et al. (2006) and Jardine and Standing (2012) detailed the test piles' layout plan (Figure 4), pile tension testing set-up (Figure 5), and geotechnical profiling, which included multiple cone penetrometer test (CPT), DMT and seismic soundings as well as extensive laboratory tests on samples from a $26 \mathrm{~m}$ deep borehole. The site profile (Figure 6) consists of $3 \mathrm{~m}$ of hydraulic marine sand fill overlying an extensive depth of Flandrian marine sand deposited over three local transgressions between 2100 and 900 years BP (Sommé, 1969). The Dunkerque profile includes an organic layer between $7.6 \mathrm{~m}$ and $8.2 \mathrm{~m}$, associated with sea-level transgressions, and two further, deeper organic bands. The CPT $q_{\mathrm{c}}$ tip resistances vary with depth between 10 and $35 \mathrm{MPa}$, averaging around $21 \mathrm{MPa}$ over the $19 \mathrm{~m}$ pile lengths. The groundwater table was reported at $4 \mathrm{~m}$, showing no tidal variations. The

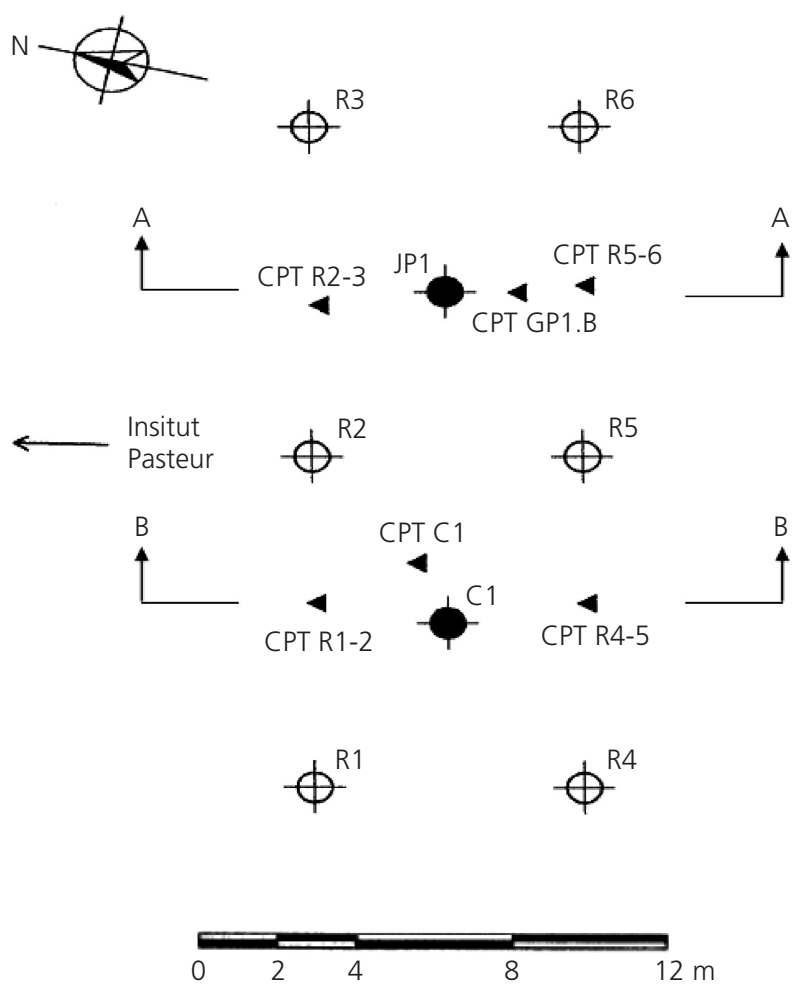

Figure 4. Plan showing layout of test and reaction piles and CPTs from GOPAL project in Dunkerque, France (after Jardine and Standing, 2012) sands' particle size distributions (PSD) are shown in Figure 7, and other index properties are given in Table 2. Summary observations are given in Table 3 regarding the site-specific laboratory characterisation reported by Chow (1997), supplemented by extensive advanced laboratory testing by Kuwano (1999). Jardine et al. (2005b) showed that the piles' static load-displacement characteristics can be reproduced with reasonable accuracy by non-linear finite-element analyses based on

(a) the non-linear laboratory stiffness data

(b) local shaft stress distributions assessed through the ICP procedures (incorporating allowance for pile-soil interface slip, as described by Jardine et al., 2005a)

(c) allowance for the pile ageing behaviour.

\section{Scaling of tests}

Any application of the cyclic pile test results should consider how they may scale to the problem in hand. The key points to consider are the pile slenderness ratio $L / D$, and the effective axial stiffness of the piles compared with the shear stiffness of the soil mass. The pile stiffness depends on the steel modulus, the pile wall thickness $(t)$ and outside diameter. Pile $\mathrm{C} 1$ had an $L / D \approx 22$, whereas $\mathrm{R} 1$ to $\mathrm{R} 6$ had $L / D \approx 42$. The latter $L / D$ value is typical of many offshore jacket piles, but lower values are typical for monopiles and possibly for multi-pile wind turbine structures. All the test piles had $D / t$ ratios of 33.8 over most of their embedded lengths, which may be typical of jacket structures, but are low for wind turbine installations (Jardine, 2008; Merritt et al., 2012). The Dunkerque conditions may be typical for southern North Sea sites, but greater stiffness can be expected at denser sand sites, where $q_{\mathrm{c}}$ values exceed $50 \mathrm{MPa}$.

In cases where the pile make-up and soil stiffness characteristics are clearly different, the global cyclic stability diagrams can be reformulated to consider local cyclic degradation processes through a cyclic $T-z$ approach, as summarised for example by Puech et al. (2012) and applied to the Dunkerque case by Atkins Consultants Ltd (2000) using an approach such as that outlined in the ICP design procedures (Jardine et al., 2005a), and detailed in Jardine and Standing (2012).

\section{Test programme}

The cyclic testing programme performed is detailed in Table 4 . Note that only static tests were performed on pile R1. Pile-head loads were controlled by an automated hydraulic system and beam arrangement supplied by Precision Measurement and Control (PMC) Ltd of Teesside UK (Jardine et al., 2006). The loads applied were measured through a high-quality load cell, and displacements were monitored by four LVDTs fixed to reference beams supported by steel poles driven at least $3 \mathrm{~m}$ away from the reaction system (Figure 5). The axial cyclic loading was controlled by a regulator that imposed near-sinusoidal waves with maxima and minima that could be controlled to within $\pm 5 \mathrm{kN}$ over long-duration tests. The cyclic rates ranged between 1 and 2 min per cycle, depending on the pile response. 


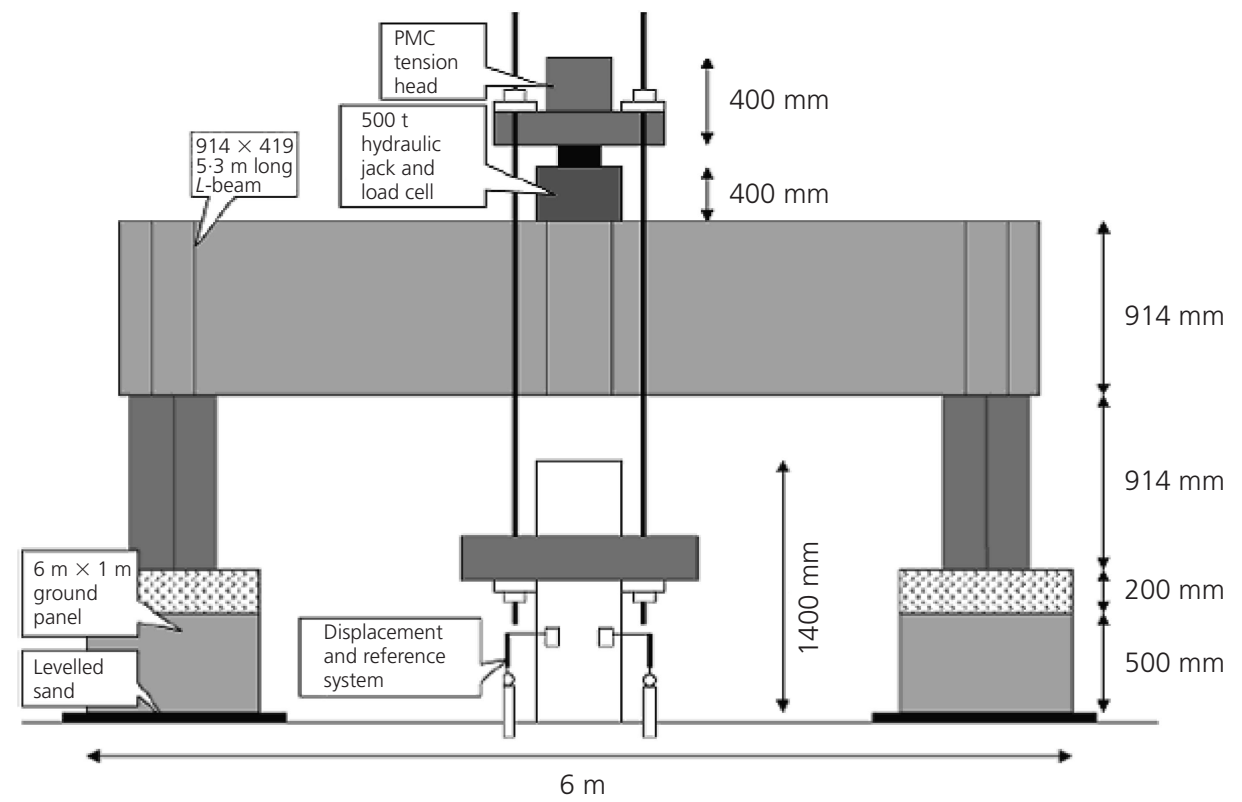

(a)

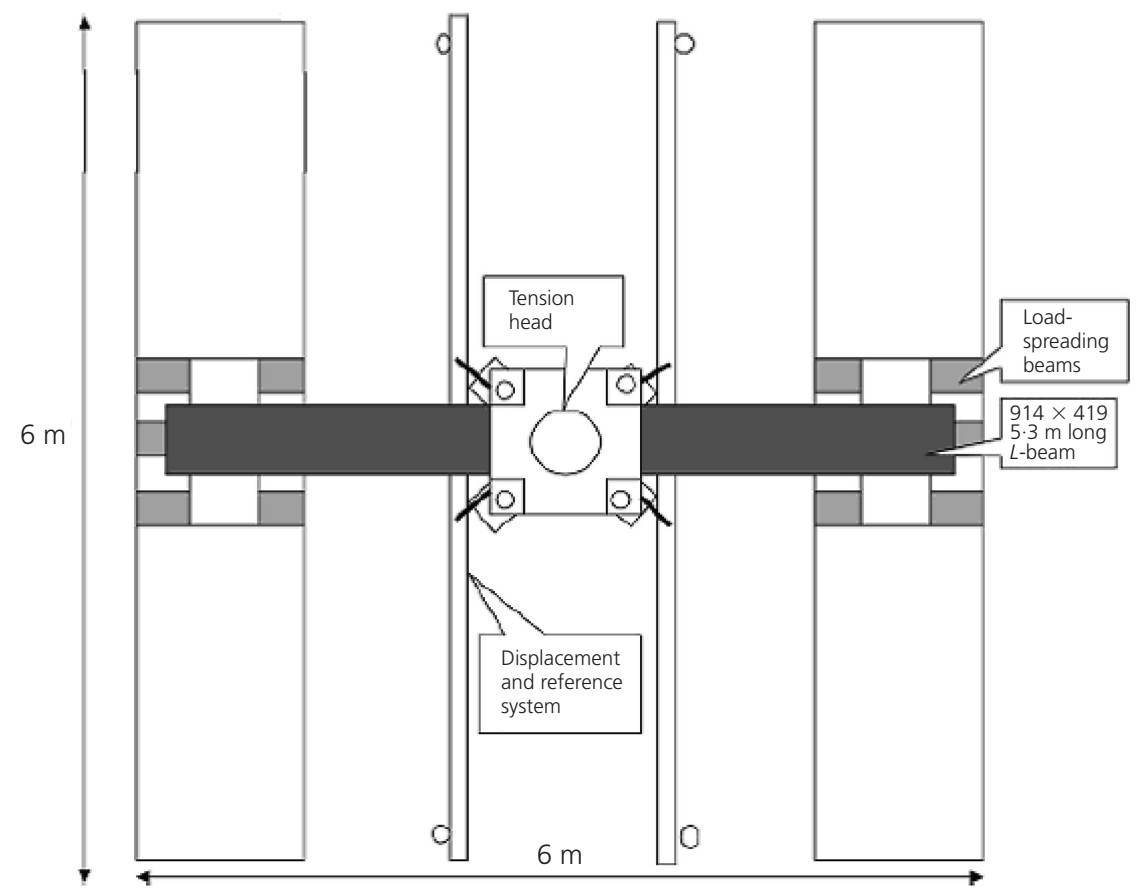

(b)

Figure 5. Details of test rig (not to scale) (after Jardine et al., 2006): (a) elevation; (b) plan

The test code sequence given in Table 4 refers to the testing phase (of which there were three), the pile identifier (e.g. R2), and then the test type $(\mathrm{CY}=$ cyclic, $\mathrm{T}=$ static tension $)$ and number of tests for the respective pile. No cycling was conducted in phase 1. The cyclic programme was organised into two campaigns: phase 2, October-November 1998; and phase 3, April 1999. The load-controlled tests involving only tensile pile-head loads are termed 'one-way', and tests where cycles ranged from tension to compression are referred to as 'two-way'; tension loads and upward displacement responses are taken as positive throughout. Definitions relating to cyclic loading are shown in Figure 1. Reference static tension tests to failure (T) were conducted after most of the cyclic tests. These were performed to assess the effects of the applied axial cyclic loading on the operational static 


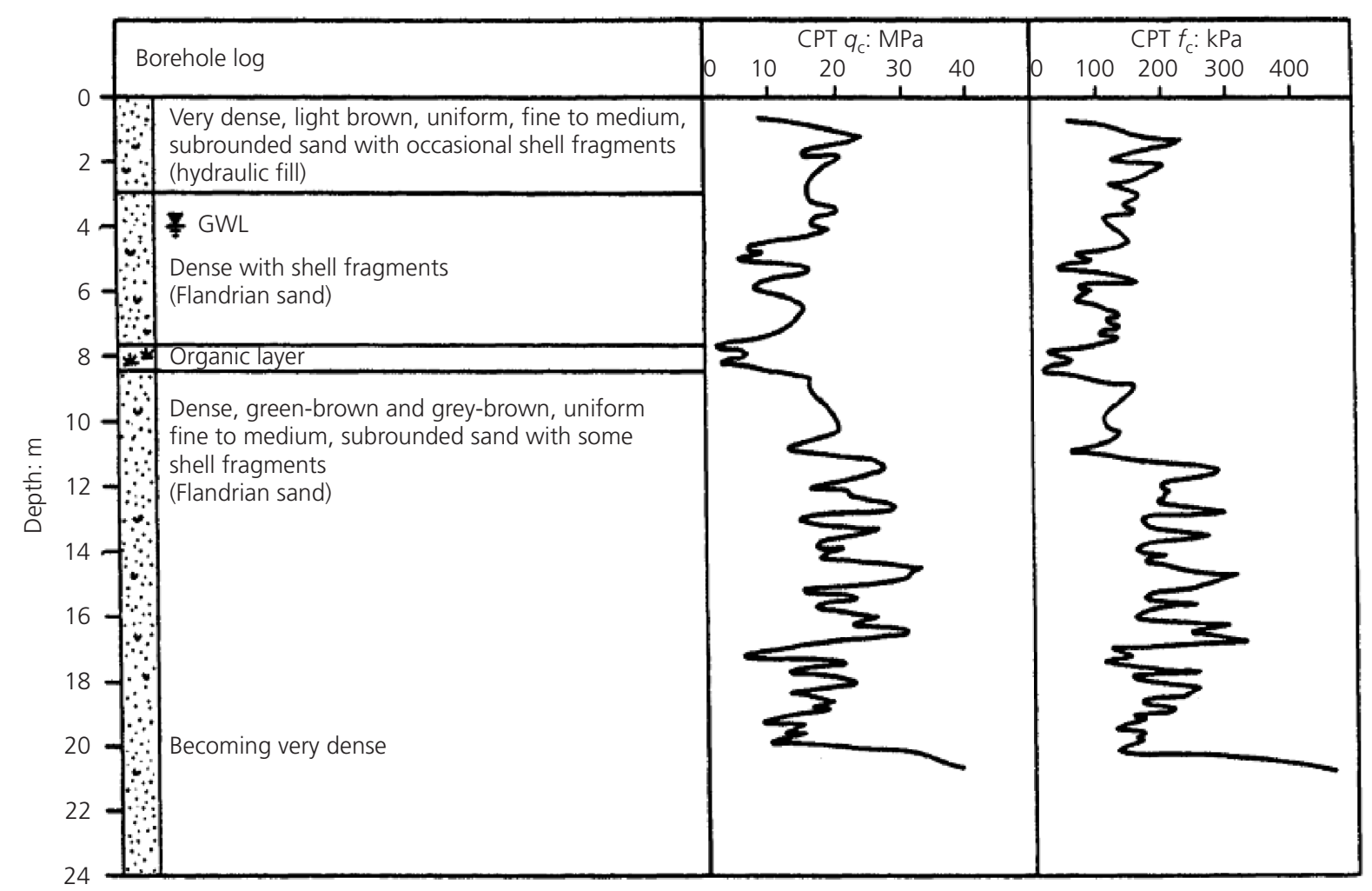

Figure 6. Typical site profile for CLAROM/ Imperial College test site (Jardine et al., 2006)

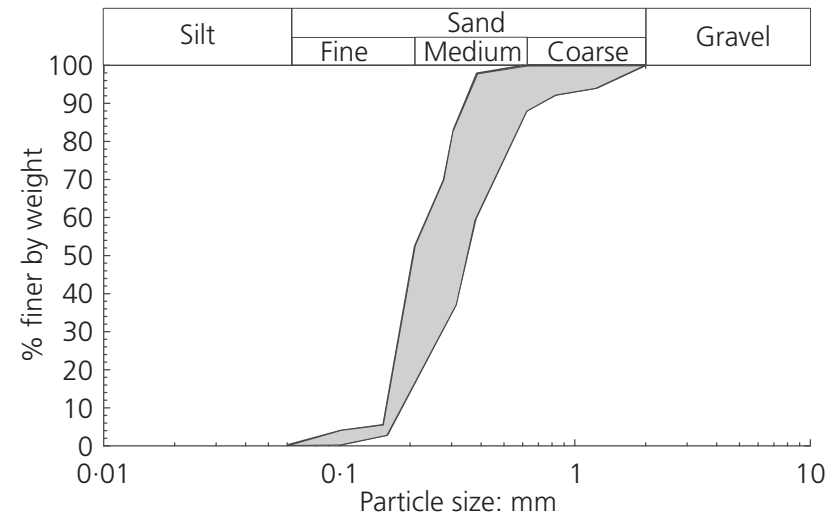

Figure 7. Particle size distributions envelope of Dunkerque sand (after Jardine and Standing, 2000) tension (shaft) capacity. The static tests similarly served to isolate any effects of previous (static or cyclic) loading phases from the current axial cyclic behaviour. Table 5 summarises the load test capacities.

\section{Results and interpretation}

\subsection{Cyclic failure criteria}

Following Tsuha et al. (2012) and Jardine and Standing (2012), the axial cycling displacement responses are classified as stable, metastable or unstable, applying the following criteria.

(a) Stable (S): Low and stabilising accumulated axial displacements that remain below $0 \cdot 01 D$ and show slow rates of change ( $\leqslant 1 \mathrm{~mm} / 1000$ cycles) up to $N \geqslant 1000$ without causing any loss of operational static shaft capacity.

\begin{tabular}{lccccc}
\hline Specific gravity, $\mathrm{G}_{\mathrm{S}}$ & $\mathrm{SiO}_{2}: \%$ & Feldspar: \% & $\mathrm{CaCO}_{3}: \%$ & Average $\gamma_{\text {sat }}: \mathrm{kN} / \mathrm{m}^{3}$ & Average $I_{\mathrm{D}}: \%$ \\
\hline 2.656 & 84 & 8 & 8 & 19.9 & 75
\end{tabular}

Table 2. Index properties of Dunkerque sand 


\begin{tabular}{|c|c|c|}
\hline Test & Parameter & Reference \\
\hline$K_{0}$ consolidated undrained $\left(C K_{0} U\right)$ triaxial stress path tests $\left(K_{0}=0 \cdot 35\right), I_{D}=\sim 75 \%$ & $\begin{array}{l}\text { Compression } \phi_{p}^{\prime}=37^{\circ} \\
\text { Extension } \phi_{p}^{\prime}=35^{\circ} \\
\text { Critical state } \phi_{c s}^{\prime}=32^{\circ}\end{array}$ & $\begin{array}{l}\text { Kuwano } \\
\text { (1999) }\end{array}$ \\
\hline $\begin{array}{l}K_{0} \text { consolidated undrained }\left(C K_{0} U\right) \text { triaxial stress path tests }\left(K_{0}=0.35\right) \text {, shear modulus at } \\
\varepsilon_{S}=0.005 \%, I_{D}=\sim 75 \%\end{array}$ & $\begin{array}{l}G_{\text {compression }}=111 \mathrm{MPa} \\
G_{\text {extension }}=230 \mathrm{MPa}\end{array}$ & $\begin{array}{l}\text { Kuwano } \\
(1999)\end{array}$ \\
\hline Sand direct shear tests, $\sigma_{\mathrm{n}}^{\prime}=40-300 \mathrm{kPa}$ & $\begin{array}{l}\phi_{\mathrm{cs}}^{\prime}=31 \cdot 1^{\circ} \\
\phi_{\mathrm{p}}^{\prime}=39 \cdot 4^{\circ}\end{array}$ & $\begin{array}{l}\text { Kuwano } \\
(1999)\end{array}$ \\
\hline Sand-mild steel interface $\left(R_{\mathrm{cla}}=9.8 \mu \mathrm{m}\right)$ direct shear test & $\begin{array}{l}\delta_{\mathrm{p}}^{\prime}=30 \cdot 8^{\circ} \\
\delta_{\mathrm{cv}}^{\prime}=26 \cdot 8^{\circ}\end{array}$ & \\
\hline Aged sand-stainless steel interface $\left(R_{\mathrm{cla}}=9.8 \mu \mathrm{m}\right)$ direct shear tests, 63 days' ageing & $\begin{array}{l}\delta_{\mathrm{p}}^{\prime}=31 \cdot 0^{\circ} \\
\delta_{\mathrm{cv}}^{\prime}=27 \cdot 5^{\circ}\end{array}$ & Chow (1997) \\
\hline
\end{tabular}

No change of either $\delta_{c v}^{\prime}$ or $\delta_{p}^{\prime}$ with ageing. Creep densification, increased shear stiffness and stronger dilation with ageing supposedly from microstructural rearrangement of the sand grains and their contacts.

Table 3. Mechanical properties of Dunkerque sand

\begin{tabular}{llrrrc}
\hline Test mode & Test code & $Q_{\text {cyclic }}: k N$ & $Q_{\text {mean }}: k N$ & $Q_{T}: k N$ & $N_{f}$ \\
\hline One-way & US 3.R2.CY2 & 1000 & 1000 & 2500 & 9 \\
& MS 2.R3.CY2 & 700 & 700 & 2315 & $200+$ \\
& US 2.R3.CY3 & 950 & 950 & 2050 & 13 \\
& MS 2.R4.CY2 & 1000 & 1000 & 2960 & $221+$ \\
& US 2.R4.CY4 & 750 & 1250 & 2000 & 3 \\
& S 3.R4.CY6 & 400 & 405 & 2110 & $1000+$ \\
& MS 2.R5.CY2 & 750 & 1250 & 2465 & 345 \\
& US 2.R5.CY3 & 700 & 700 & 2000 & 27 \\
& US 2.R6.CY2 & 750 & 1250 & 2000 & 1 \\
& US 2.R6.CY4 & 700 & 700 & 1585 & 24 \\
& MS 3.R6.CY6 & 700 & 700 & 1650 & 206 \\
TS 2.C1.CY3 & 620 & -40 & 840 & 41 \\
Two-way & US 2.C1.CY4 & 445 & 165 & 620 & 1 \\
& US 2.C1.CY5 & 410 & 10 & 620 & 12 \\
\hline
\end{tabular}

Test code explained (XX M.YY.ZZN):

$X X=$ pile response mode ( $\mathrm{S}$, stable; MS, metastable; US, unstable)

$M=$ testing campaign phase (out of 3 )

$Y Y=$ pile name $(C 1, R 1-R 6)$

$Z Z$ = test type ( $T$, static tension; $C$, static compression; $C Y$, axial cyclic)

$N=$ test number on pile in sequence from installation.

Table 4. Axial cyclic loading testing programme (from Jardine and

Standing, 2000)

(b) Metastable (MS): Axial displacements accumulate $(0 \cdot 01 D<$ accumulated displacements $\leqslant 0 \cdot 1 D)$ at moderate rates $(1 \mathrm{~mm} / 1000$ cycles $<$ rates $\leqslant 1 \mathrm{~mm} / 10$ cycles $)$, potentially leading to some degradation of the operational static shaft capacity, but not causing failure within 100 cycles.

(c) Unstable (US): Cyclic failure within 100 cycles, involving either accumulated permanent cyclic displacements $>0 \cdot 1 \mathrm{D}$ or rates of accumulation of permanent cyclic displacements that increase to $>1 \mathrm{~mm} / 10$ cycles. Shaft capacity degradation is potentially very significant.

The cyclic tests are reported and analysed with reference to the cyclic stability interaction diagram shown in Figure 2 from Jardine and Standing (2012). The static tension capacities varied with time and cyclic loading history. The reference $Q_{\mathrm{T}}$ values employed in Figure 2 are those applying at the time of testing. 


\begin{tabular}{|c|c|c|}
\hline Test code & Tension capacity: kN & Comment \\
\hline 1.R1.T1 & 1440 & Ductile failure \\
\hline 3.R2.T1 & 3200 & Ductile failure \\
\hline 3.R2.T3 & 1655 & 'Stick-slip' failure \\
\hline 2.R3.T1 & $2000 *$ & No failure on loading to $10.3 \mathrm{~mm}$ displacement \\
\hline 2.R3.T4 & $\sim 1655$ & 'Stick-slip' failure in 'quick' test \\
\hline 3.R3.T5 & 1990 & Brittle 'stick-slip' failure \\
\hline 2.R4.T1 & 2000 * & No failure on loading to $8.7 \mathrm{~mm}$ displacement \\
\hline 2.R4.T3 & $\sim 2000$ & Failure in 'quick' test \\
\hline 2.R4.T5 & $\sim 2000$ & Brittle 'stick-slip' failure, reducing to $\sim 1450 \mathrm{kN}$ \\
\hline 3.R4.T7 & $\sim 2490$ & Brittle 'stick-slip' failure (reducing to $\sim 1900 \mathrm{kN}$ ) in 'quick' test \\
\hline 2.R5.T1 & $2000 *$ & With 8.9 mm displacement; estimated capacity 2450 kN \\
\hline 2.R5.T4 & $\sim 1300$ & 'Stick-slip' failure in 'quick' test \\
\hline 3.R5.T5 & $\sim 1795$ & Brittle failure reducing to $1636 \mathrm{kN}$ \\
\hline 2.R6.T1 & 2400 & With 30 mm displacement; estimated capacity 2450 kN \\
\hline 2.R6.T3 & 1585 & Ductile failure \\
\hline 2.R6.T5 & $\sim 1325$ & 'Stick-slip' failure in 'quick' test \\
\hline 3.R6.T7 & $\sim 1425$ & 'Stick-slip' failure \\
\hline 2.C1.C1 & -2820 & After $34 \mathrm{~mm}$, load at $46 \mathrm{~mm}$ estimated at $-2850 \mathrm{kN}$ \\
\hline 2.C1.T2 & $\sim 820$ & 'Stick-slip' tension \\
\hline 2.C1.T6 & $\sim 500$ & 'Stick-slip' failure at $46 \mathrm{~mm}$ \\
\hline
\end{tabular}

* Tests curtailed at maximum initial rig capacity of $2000 \mathrm{kN}$.

Table 5. Reference static tension capacities (from Jardine and

Standing, 2000)

The ranges of cyclic loading conditions $\left(Q_{\text {mean }}, Q_{\text {cyclic }}\right)$ considered are normalised by the current reference static capacity, $Q_{\mathrm{T}}$. The diagonal line $\left(Q_{\text {mean }} / Q_{\mathrm{T}}, Q_{\text {cyclic }} / Q_{\mathrm{T}}\right)(1,0)$ to $(0,1)$ forms the upper static limit $(N=1)$. Rate effects in shaft capacity are likely to be small in sands, and the pile-loading cases are mapped into cyclic stability zones, which are assigned to conform broadly to the number of cycles required to induce cyclic failure under the specified conditions. The cyclic loading experienced in service by offshore driven piles may involve millions of low-level cycles, while severe storms are likely to impose a relatively small number of severe load cycles. Recovery of capacity degradation can take place between severe storms (Jardine and Standing, 2000).

The 14 load-controlled axial cyclic tests gave a range of outcomes, with one stable loading (set 1), four metastable loading (set 2) and nine unstable loading (set 3) responses indicated in Figure 2. In analysing the cyclic loading data, displacements have been assessed in two ways. The permanent accumulated cyclic displacement, shown as $a$ in Figure 8, is cumulative, usually increasing with the number of cycles. It is measured with respect to the $Q_{\max }$ point of the first cycle (see Figures 1 and 8 ). The second measure of displacement, $d$, is the transient cyclic displacement that occurs for each cycle, and which may increase with cycling, especially under metastable and unstable loading conditions. Analyses of how the piles'

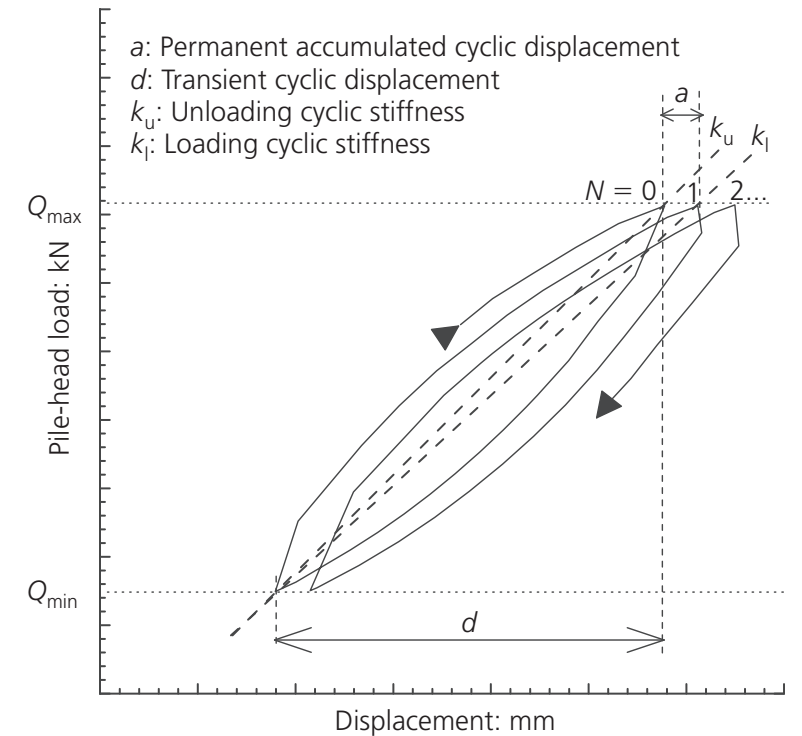

Figure 8. Illustration of stiffness and displacement parameters used in analyses

axial cyclic stiffness (defined in Figure 8) responses, permanent accumulated cyclic displacements and the transient cyclic displacements evolved with number of cycles during cyclic loading are now presented. 


\subsection{Pile axial cyclic stiffness}

Figure 9 plots load-displacement results from slow, maintainedload, first-time tension tests for seven of the piles driven at Dunkerque (i.e. tests 2.C1.T2, 1.R1.T1, 3.R2.T1, 2.R3.T1, 2.R4.T1, 2.R5.T1 and 2.R6.T1 from Table 5). The initial maximum reference secant stiffness $k_{\mathrm{Ref}}=\Delta Q / \Delta s$ is defined by considering the first load step applied (defined as $Q_{\text {Ref }}$ ), which was $100 \mathrm{kN}$ for $\mathrm{C} 1$ and $200 \mathrm{kN}$ for R1 to R6. As noted by Jardine et al. (2005b), the piles' load-displacement behaviour is highly non-linear. In Figure 10 the piles' secant stiffness non-linearity, assessed from the first-time tension loading tests shown in Figure 9 , is represented by plotting the stiffnesses ratio, $k / k_{\mathrm{Ref}}$, against the ratio $Q / Q_{\text {Ref. }}$ Piles $\mathrm{R} 2$ to $\mathrm{R} 6$ (19 $\mathrm{m}$ long) show trends

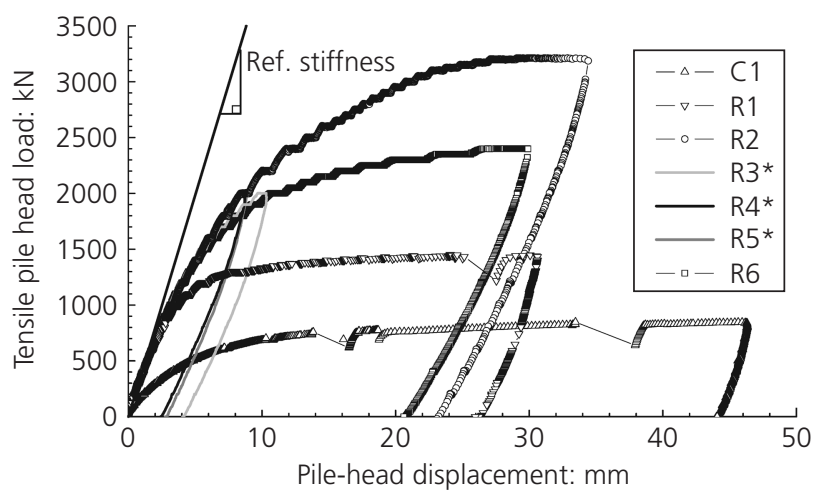

Figure 9. Load-displacement curves for first-time monotonic tension load tests. ${ }^{*}$ Tests curtailed at maximum initial rig capacity

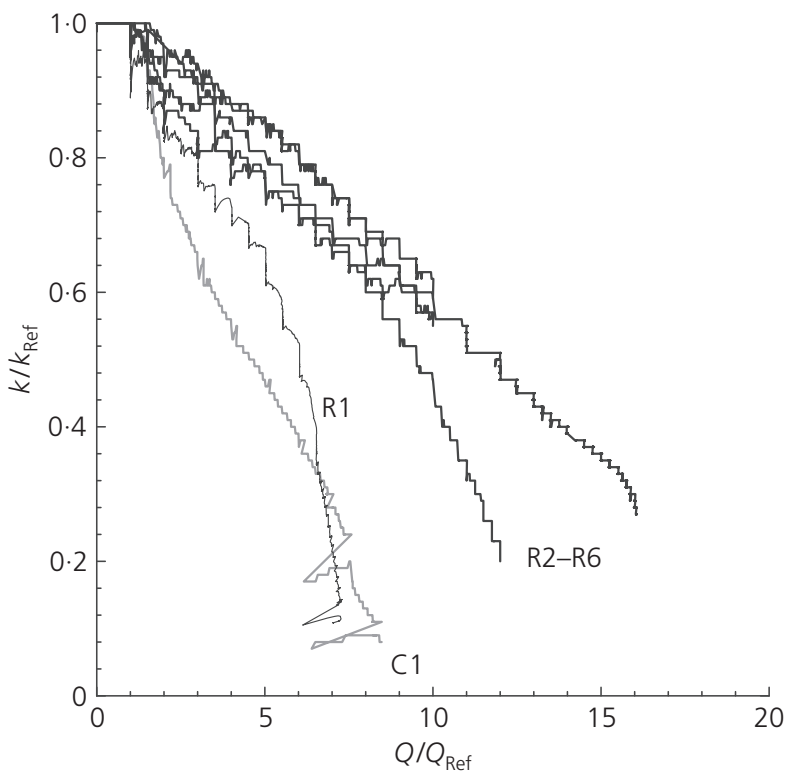

Figure 10. Stiffness degradation of piles assessed from the firsttime axial static monotonic tension loadings normalised by the reference stiffnesses plotted against load normalised by $Q_{\text {Ref }}$ common to but stiffer than the lower ultimate capacity $19 \mathrm{~m}$ long pile $\mathrm{R} 1$, which is stiffer than the shorter (10 $\mathrm{m}$ long) pile $\mathrm{C} 1$.

The stiffness response under cycling is considered using the variables defined in Figure 8. Note that different cyclic stiffness values $k_{1}$ or $k_{\mathrm{u}}$ may develop on the loading and unloading paths of cyclic loading respectively. The loading cyclic stiffness values, $k_{1}$, are considered first in relation to the reference stiffness $k_{\text {Ref }}$, as shown in Figure 11(a) (stable and metastable tests) and Figure 12(a) (unstable tests) to examine the evolution of the piles' stiffness under axial cycling. Figures 11(b) and 12(b) show the same data, but with the $k_{1}$ values normalised by the loading

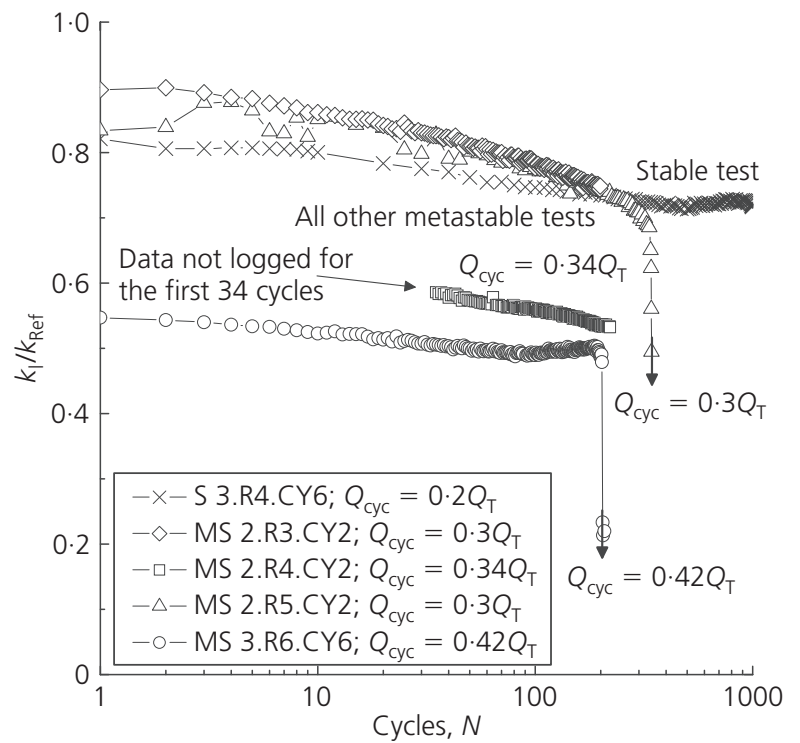

(a)

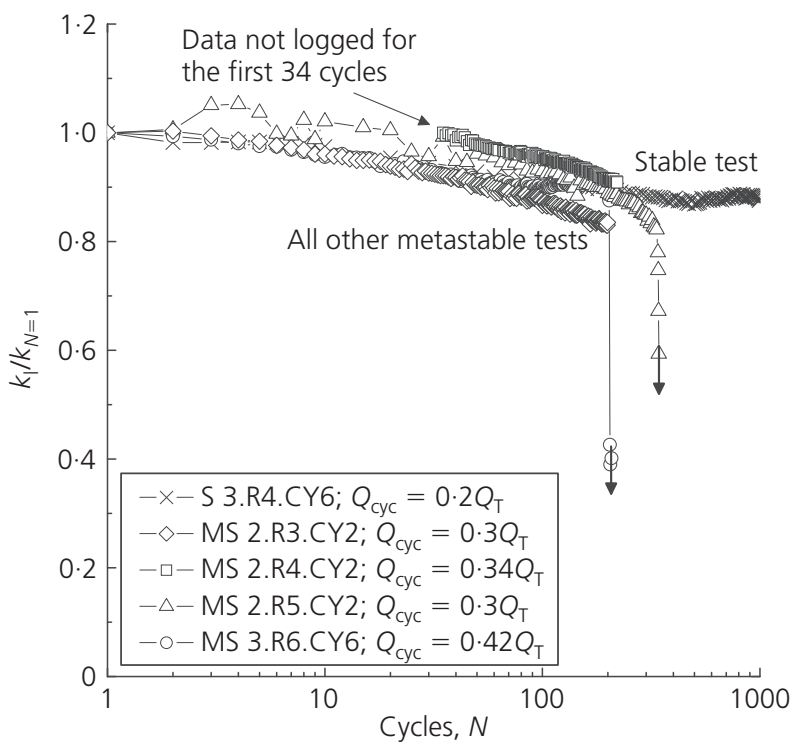

(b)

Figure 11. Axial cyclic loading stiffness $\left(k_{1}\right)$ responses normalised in terms of (a) $k_{\text {Ref }}$ and (b) $k_{N=1}$, plotted against number of cycles for stable and metastable loading tests 


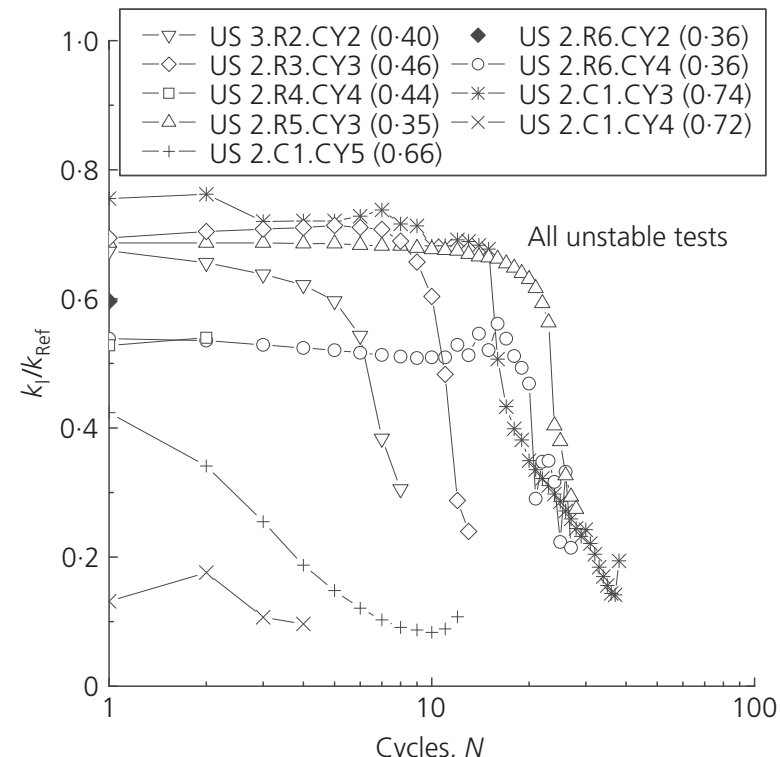

(a)

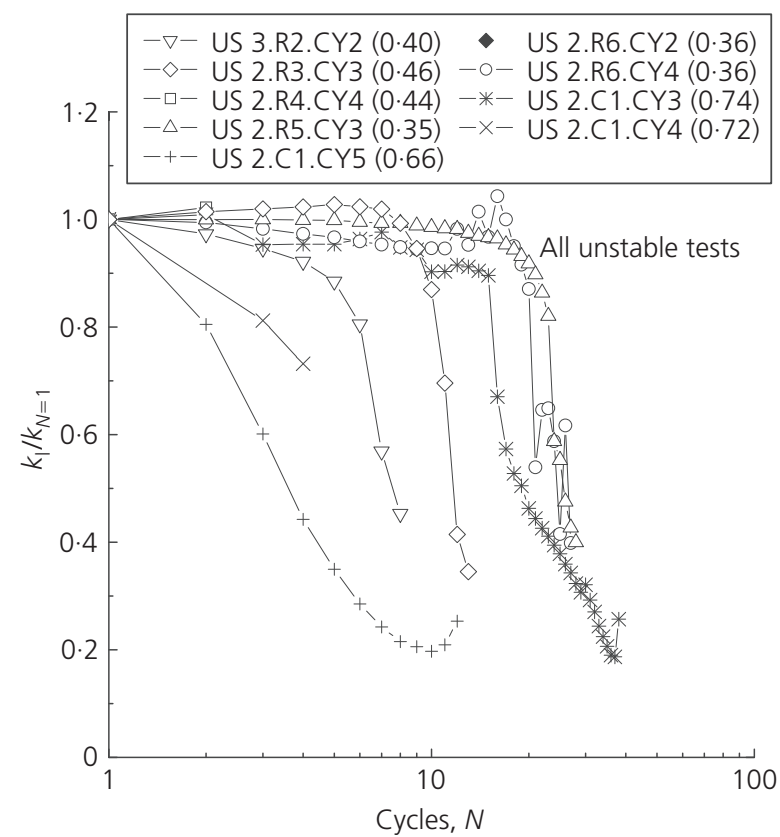

(b)

Figure 12. Axial cyclic loading stiffness $\left(k_{l}\right)$ responses normalised in terms of (a) $k_{\text {Ref }}$ and (b) $k_{N=1}$, plotted against number of cycles for unstable loading tests

stiffness measured over the first loading cycle of each particular test, $k_{N=1}$.

Figure 11(a) shows the results from the stable and metastable axial cycling tests (sets 1 and 2 in Figure 2), with the $Q_{\text {cyclic }}$ value for each test marked in the legend. For the metastable loading tests, the initial normalised stiffness values (i.e. $k_{1} / k_{\operatorname{Ref}}$ at $N=1$ ) clearly reduce as $Q_{\text {cyclic }}$ increases, as expected given the piles' non-linear static response (the greater the proportion of $Q_{\mathrm{T}}$ applied in the cycle, the smaller the initial secant stiffness). The two tests where cycling is applied at $0 \cdot 3 Q_{\mathrm{T}}$ (MS 2.R3.CY2 and MS 2.R5.CY2) follow roughly the same path, except that there is some scatter in the early data of the latter test. The initial normalised stiffness for the stable loading test where the cycling is applied at $0.2 Q_{\mathrm{T}}$ (S 3.R4.CY6) is in fact slightly lower than the value for the $Q_{\text {cyclic }}=0 \cdot 3 Q_{\mathrm{T}}$ tests. It can be seen that continued cycling leads to only a marginal stiffness decrease $(12 \%)$ over 1000 cycles in this stable loading 3.R4.CY6 test, with stiffness values stabilising, or even marginally increasing, after 200 cycles. Compared with this stable test, the unfailed metastable loading tests 2.R3.CY2 and 2.R4.CY2 showed marginally more pronounced final stiffness degradations (of about $16 \%$ ) up to the end of cycling. The failed metastable loading tests 2.R5.CY2 and 3.R6.CY6 showed similar trends over most of the cycling duration, until sharp stiffness degradation set in as the piles approached cyclic failure under the conditions given in Table 4 . Similar trends are seen for the stiffness data normalised by $k_{N=1}$, as shown in Figure 11(b).

The loading stiffness $\left(k_{1}\right)$ degradation trends for the unstable tests (Set 3 in Figure 2) are shown in Figures 12(a) and 12(b). By definition, all of these tests underwent cyclic failure and sudden stiffness degradation before reaching 100 cycles. However, those piles that survived for longer than a few cycles retained their initial stiffness values until within a few cycles of final failure. Slight variations are seen in the sharpness of the onsets to failure under similar cyclic loading levels, perhaps as a result of the complex testing sequences. Stiffness degradation can be seen more clearly in Figure 12(b), where the loading stiffness $k_{1}$ values are normalised by the initial cyclic stiffness $k_{N=1}$.

Seemingly anomalous stiffness behaviour is observed towards failure in the metastable and unstable loading tests when stiffnesses are defined from the unloading cycle phases $\left(k_{\mathrm{u}}\right)$, as seen in Figure 13. Whereas the $\mathrm{C} 1$ pile that was subjected to two-way loading cycles exhibited the same trends in stiffness degradation for both $k_{1}$ and $k_{\mathrm{u}}$ values, several of the piles subjected to one-way loading showed a typical initial gradual decrease of normalised stiffness $\left(k_{\mathrm{u}} / k_{N=1}\right)$, but then exhibited apparently increasing $k_{\mathrm{u}}$ values as cyclic failure was approached. This reversal in normalised stiffness results from an increased opening-up of the loadunload hysteresis loops as cyclic failure approaches, with higher plastic displacements accumulating on the loading loop, and behaviour becoming increasingly dependent on cycle number. These features lead to the progressively decreasing secant loading stiffnesses and apparently stiffer behaviour on unloading as cyclic loading approaches failure.

\subsection{Permanent accumulated cyclic displacements}

The permanent accumulated cyclic pile-head displacements for the stable and metastable loading tests are shown in Figure 14, and Figure 15 refers to the unstable loading tests. Also shown in Figures 14 and 15 are reference lines relating to the rate of accumulated displacements - that is, $1 \mathrm{~mm} / 100$ cycles and $1 \mathrm{~mm} /$ 


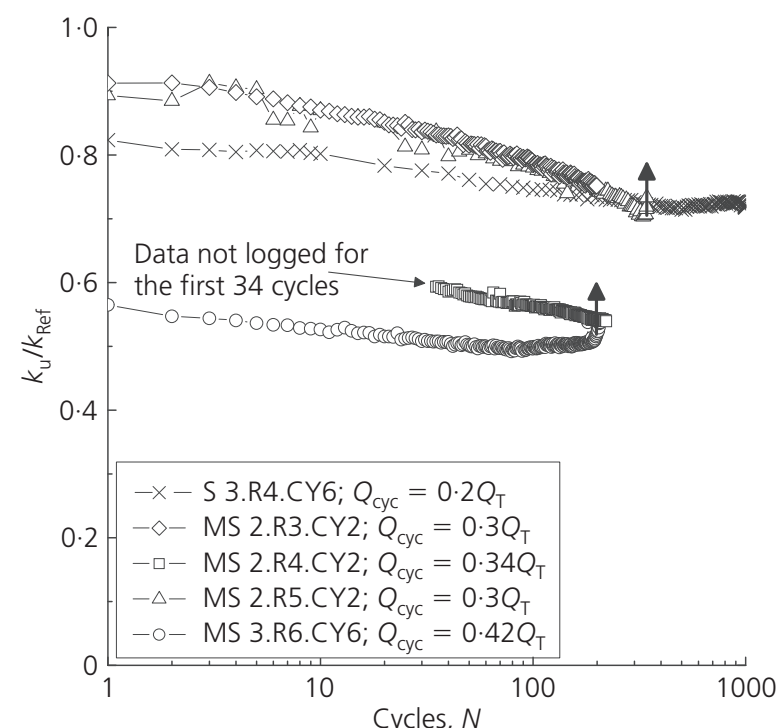

(a)

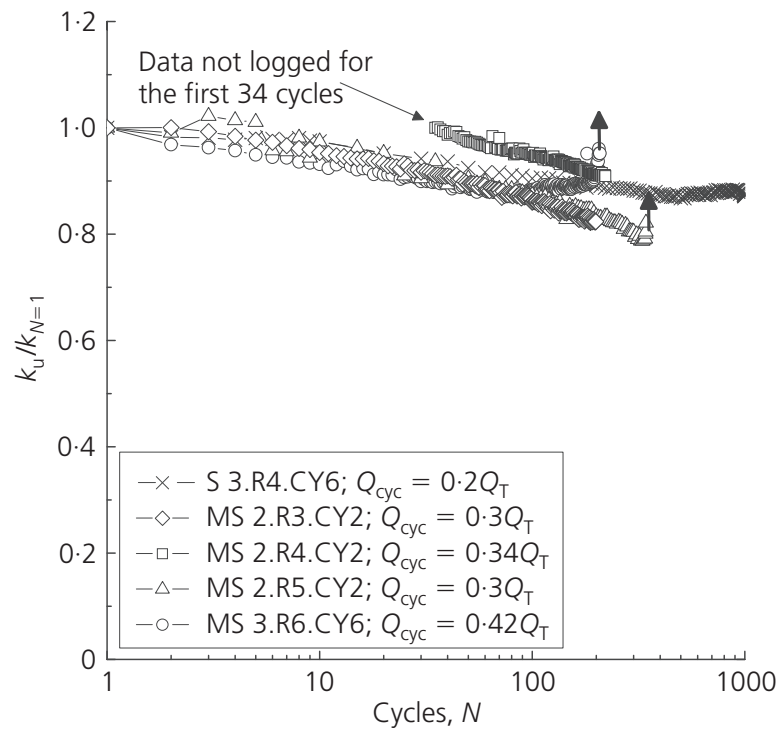

(c)

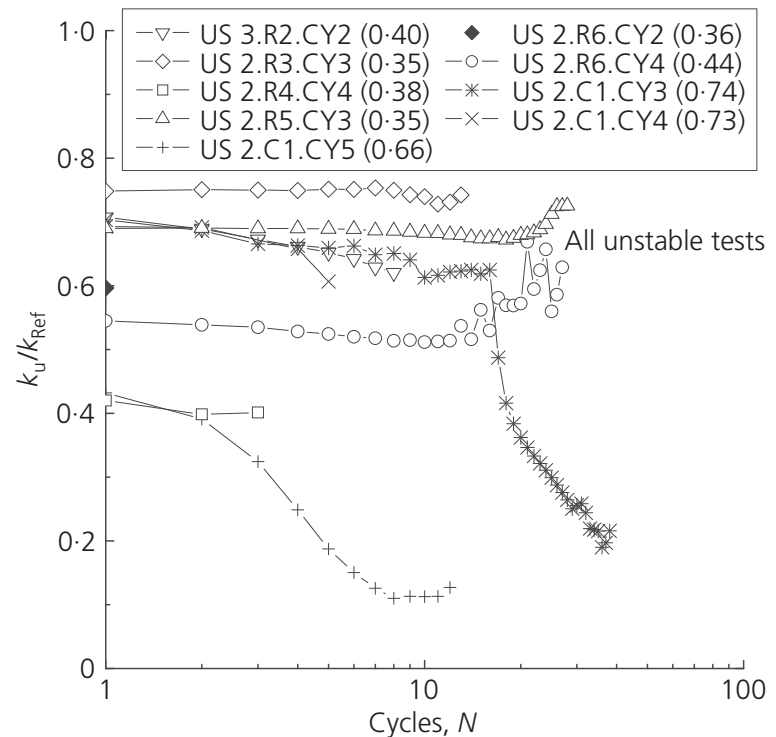

(b)

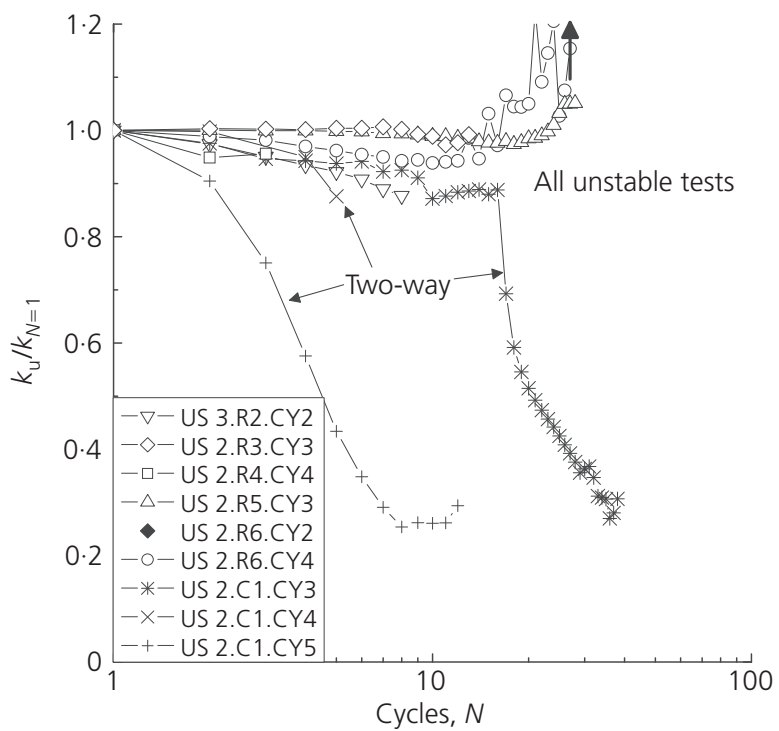

(d)

Figure 13. Axial cyclic unloading stiffness $\left(k_{u}\right)$ responses normalised in terms of (a), (b) $k_{\text {Ref }}$ and (c), (d) $k_{N=1}$, plotted against number of cycles for all cyclic loading tests

10 cycles. The rate of permanent accumulated displacements for the tests can be compared with the slopes of the two reference lines at any value of $N$. Low and stable permanent accumulated displacements were observed in the only stable loading test (3.R4.CY6), with averaged displacement rates $<0 \cdot 1 \mathrm{~mm}$ over the first 100 cycles falling to negligible or even negative rates over the final few hundred cycles. The static tension capacity test (3.R4.T7) performed after this stable cyclic series showed a gain of $24.5 \%$ in peak tension capacity (with reference to test 3.R4.T5, which defined the pre-test tension capacity). The metastable loading tests showed a range of possible behaviours. Tests 2.R3.CY2 and 2.R4.CY2 developed steady permanent accumulated displacement rates $>1 \mathrm{~mm} / 100$ cycles, and did not fail before cycling was halted after $N=200$ cycles. Quick static check tests on these piles indicated only minor losses in shaft capacity due to cycling. The other two metastable loading cyclic tests, 2.R5.CY2 and 3.R6.CY6, continued until cyclic failure occurred. The rates of permanent accumulated displacements in 2.R5.CY2 were initially high $(>1 \mathrm{~mm} / 10$ cycles $)$ but then reduced, before increasing again to $>1 \mathrm{~mm} / 10$ cycles as cyclic failure approached. However, 3.R6.CY6 started with slow rates that increased sharply to $>1 \mathrm{~mm} / 10$ cycles before a sudden and brittle cyclic failure. The loading applied in tests 2.R5.CY2 and 3.R6.CY6 resulted in a metastable response, as given by the 


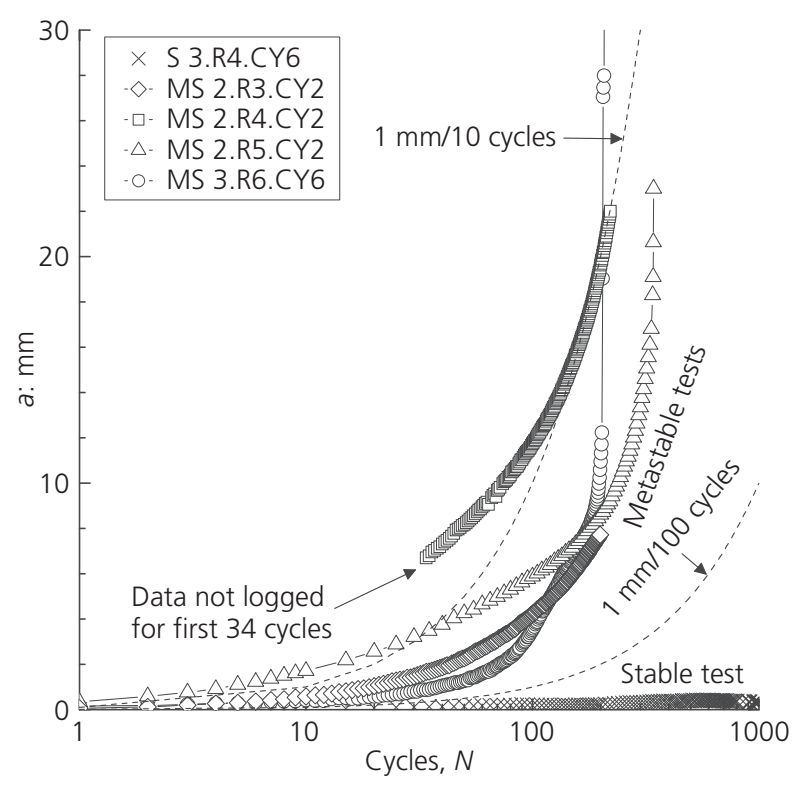

Figure 14. Permanent accumulated cyclic displacements for stable and metastable loading tests

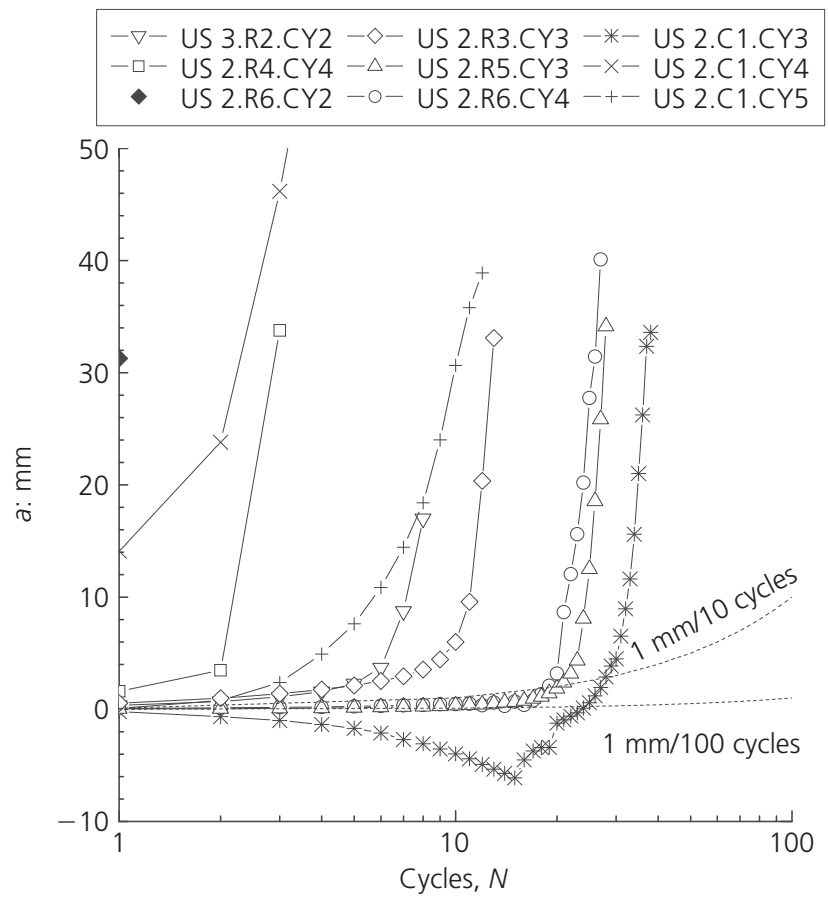

Figure 15. Permanent accumulated cyclic displacements response for unstable tests

permanent accumulated displacements and cyclic stiffness values shown over their first 100 cycles.

A range of accumulated pile-head displacement responses against number of cycles is also evident for the unstable loading tests plotted in Figure 15. Three two-way cyclic loading test suites were performed on pile C1. Test 2.C1.CY3 initially led to settlements that increased to a maximum after 15 cycles. This is because initially the compression load applied to the head of the pile $(\sim-600 \mathrm{kN})$ was greater than the tension load $(\sim 500 \mathrm{kN})$. It had been intended to apply equal compression and tension loads of $\pm 600 \mathrm{kN}$, and so after cycle $N=15$ cycling stopped for 40 minutes while the load control was adjusted (Jardine and Standing, 2012). Once this was rectified, the pile started to pull out progressively soon after cycling restarted, leading to displacement accumulation rates $>1 \mathrm{~mm} / 10$ cycles. The next test on this pile, 2.C1.CY4, performed $15 \mathrm{~h}$ later, failed the permanent accumulated cyclic displacement rate criterion within its first cycle. Test 2.C1.CY5, an experiment undertaken after a further $20 \mathrm{~h}$ of rest, exceeded the accumulated displacement rate failure criterion in two cycles, and accumulated displacements grew to $>0 \cdot 1 \mathrm{D}$ after 12 cycles, when the test was halted. An overall loss in static shaft tensile capacity of $39 \%$ accumulated between the initial and final quick static reference tests (2.C1.T2 compared with 2.C1.T6). The unstable one-way loading test 2.R4.CY4 also failed on its first cycle, with accumulated displacements approaching $0 \cdot 1 \mathrm{D}$ after three cycles. Other unstable one-way loading tests developed excessive permanent accumulated cyclic displacement rates at comparably early stages, such as 3.R2.CY2 and 2.R3.CY3, where the permanent accumulated displacements grew towards $0 \cdot 1 D$. Quick static tension tests proved shaft capacity degradations of $48 \%$ and $17 \%$ for $\mathrm{R} 2$ and $\mathrm{R} 3$ respectively. More gradual failures were observed under one-way loading in tests 2.R5.CY3 and 2.R6.CY4, where instability was indicated from the 16th cycle by the rates of permanent cyclic displacement climbing rapidly and increasing towards the displacement limit after 28 and 27 cycles respectively. The reference static tests bracketing the latter tests implied degradations in shaft capacity $>16 \%$.

Whereas the cyclic stiffness patterns varied principally as a function of the applied cyclic amplitudes $\left(Q_{\text {cyclic }}\right)$, the permanent accumulated cyclic displacement patterns were found to depend on both the normalised mean and cyclic loads. The effects of the loading components $Q_{\text {cyclic }}$ and $Q_{\text {mean }}$ are demonstrated by considering the permanent cyclic displacements developed after particular numbers of cycles $N(=3,10,30,100,200$ and 300) in relation to the normalised stability interaction chart, as shown in Figure 16. Tentative axial cyclic displacement contours equivalent to $2 \%, 0.2 \%$ or $0.02 \%$ of $D$, the piles' diameter, have been drawn by eye and linear interpolation. The contours are collated and plotted as surfaces in Figure 17, where the accumulated displacements are related to the normalised $Q_{\text {cyclic }}$ and $Q_{\text {mean }}$ values and the number of cycles, subtended with the aid of a plotting routine. The dependence of accumulated cyclic displacements on the twodimensional loading regime is clear. A tentative zero displacement (zero cyclic effect) boundary is set at $Q_{\text {cyclic }} / Q_{\mathrm{T}}=0 \cdot 1$, following centrifuge studies by Julio (2009). It is postulated that no permanent displacements accrue due to cycling beneath this surface; further full-scale specific investigation on the validity of this boundary condition is required. The accumulated cyclic 


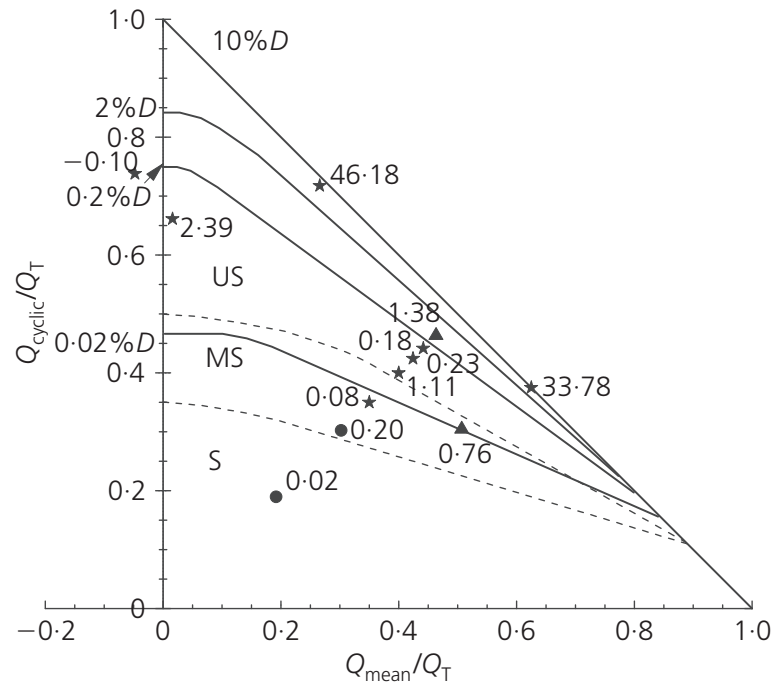

(a)

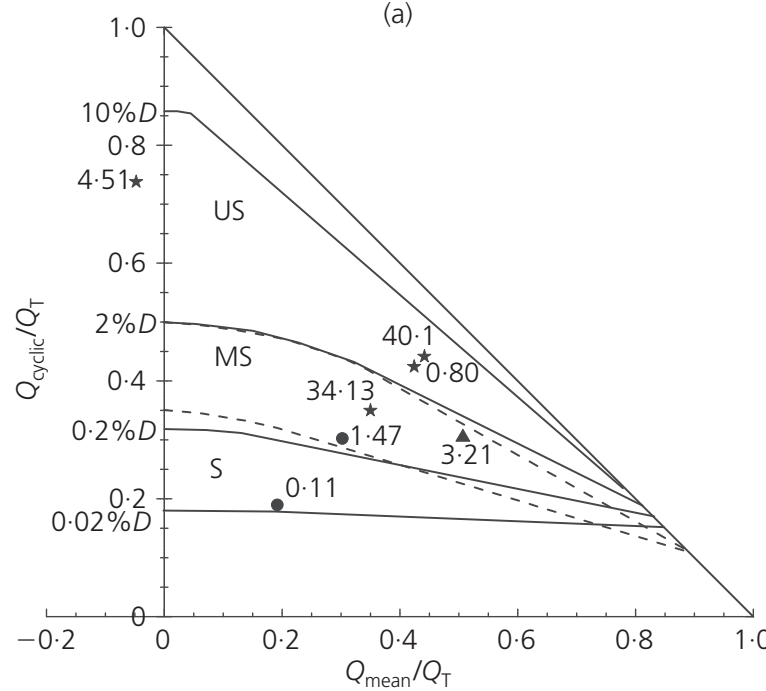

(c)

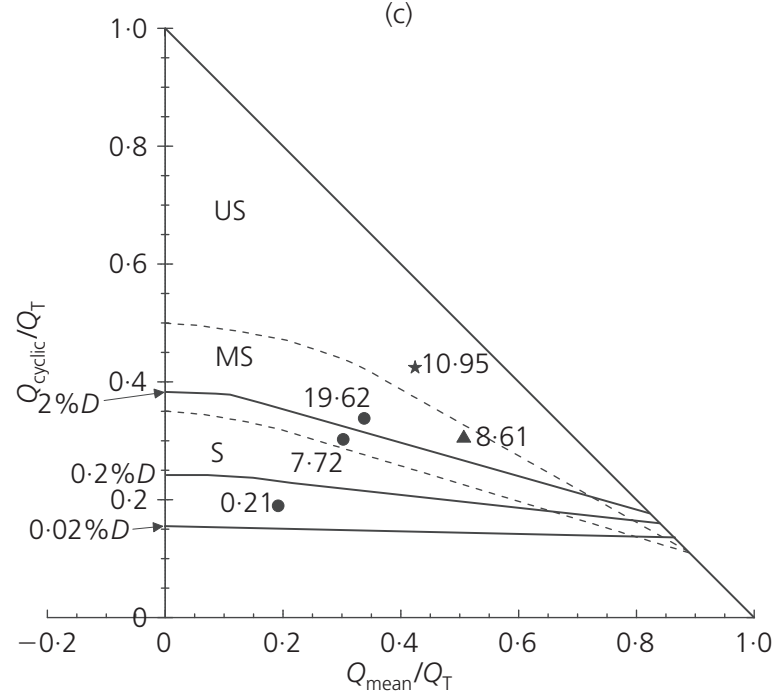

(e)

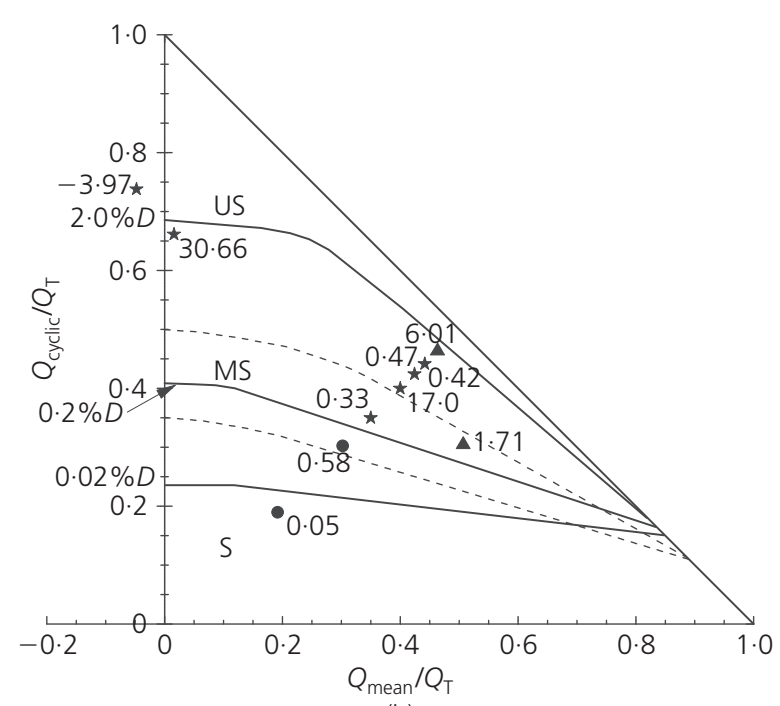

(b)

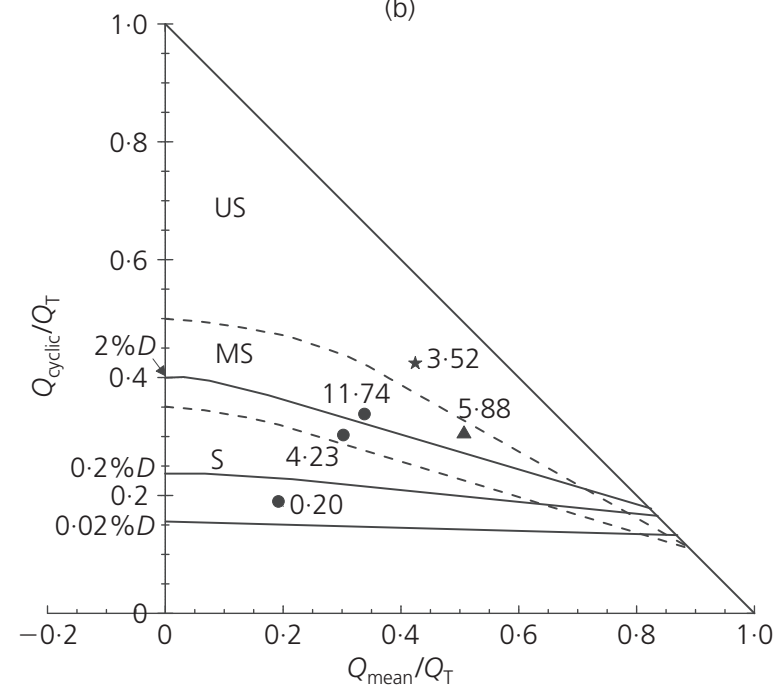

(d)

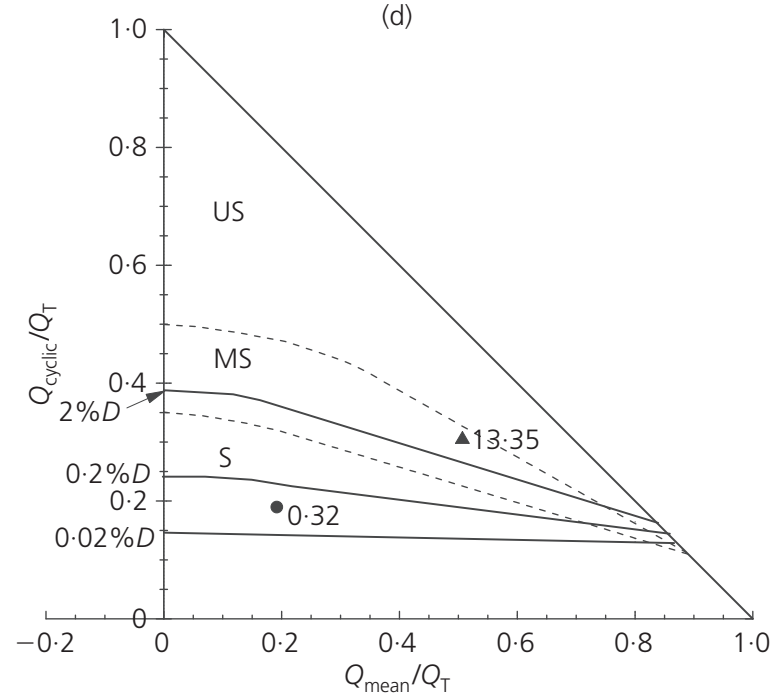

(f)

Figure 16. Axial cyclic interaction chart with accumulated displacements from cycles $N=$ (a) 3, (b) 10, (c) 30, (d) 100, (e) 200 and (f) 300, marked for cyclic pile tests 


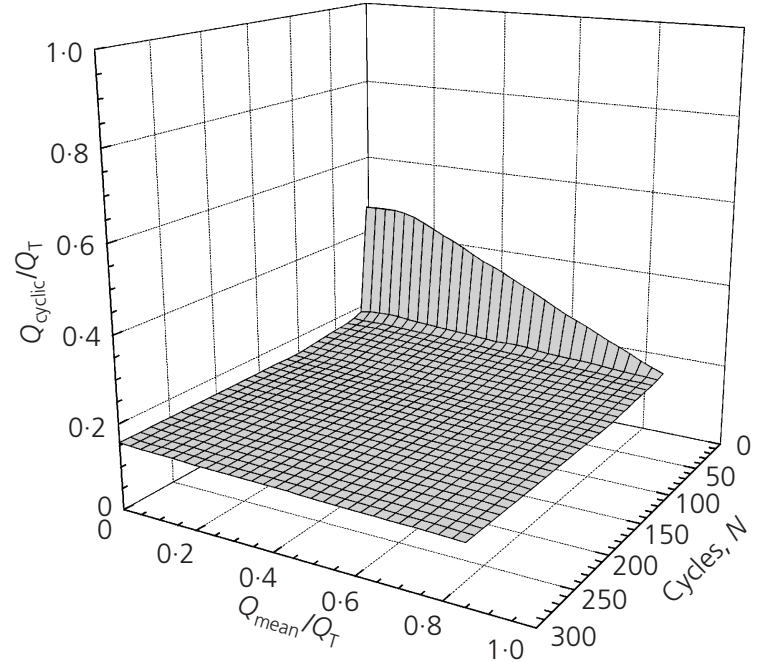

(a)

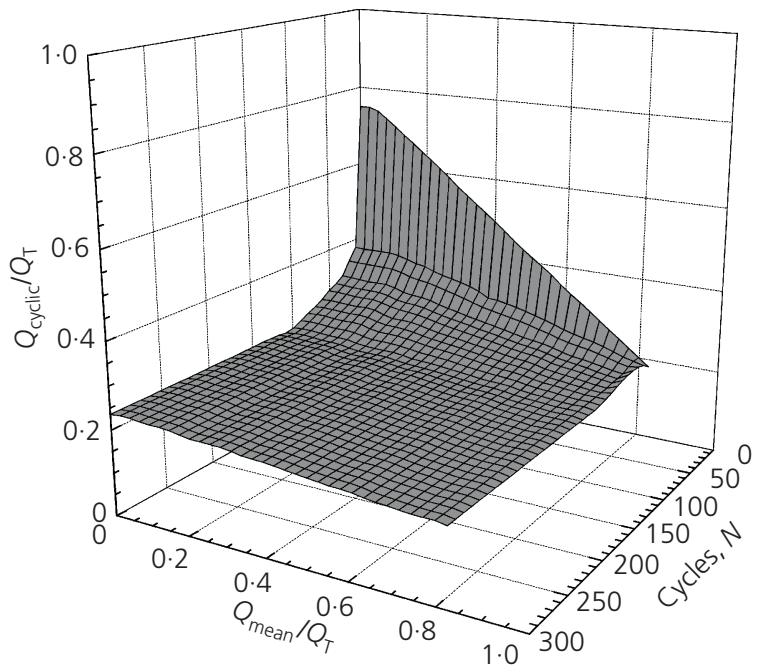

(b)

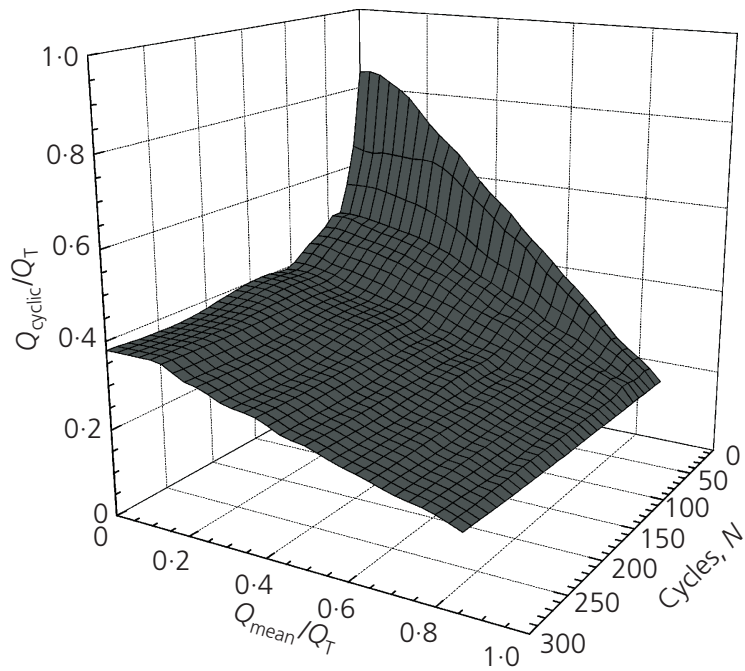

(c)

Figure 17. 3D plot for permanent accumulated cyclic displacements equivalent to (a) $0.02 \% D$, (b) $0.2 \% D$ and (c) $2 \% D$ displacements grow as cyclic amplitudes increase, and also vary with the mean loads. The axial cyclic displacement contours progressively flatten as $N$ increases.

\subsection{Transient cyclic displacements}

Trends for the transient cyclic displacements defined from the loading stages as shown in Figure 8 are considered next. The transient cyclic displacements are related to the previously discussed loading cyclic stiffness behaviour. As summarised in Figures 18 and 19, the transient cyclic displacements normalised by pile diameter $D$ increase with $Q_{\text {cyclic }}$. The stable loading test 3.R4.CY6 develops low $(\sim 0 \cdot 6 \% \mathrm{D})$ transient cyclic displacements that stabilise and begin to diminish after 500 cycles. Metastable loading tests 2.R3.CY2 and 2.R4.CY2, which did not fail under cycling, showed naturally larger transient displacements, which grew gradually to final values of $\sim 1 \% D$ and $2 \% D$ respectively. Tests 2.R5.CY2 and 3.R6.CY6, failing at 345 cycles and 206 cycles respectively, showed transient displacements growing marginally to $\sim 1 \% D$ until cyclic failure was approached, and sharp increases were seen in both transient and permanent accumulated cyclic displacements. The US tests presented in Figure 19 show transient displacements growing gradually (by 15-20\%) until the onset of cyclic failure, when transient displacements rise sharply towards or finally exceeding $5 \% D$, depending on when the tests were halted.

\section{Summary and conclusion}

It is shown in the introduction that ensuring an adequate response to axial cyclic loading is crucial to the design of multi-pile offshore wind turbine foundations. This paper discusses the behaviour observed in multiple, axially load-controlled static and

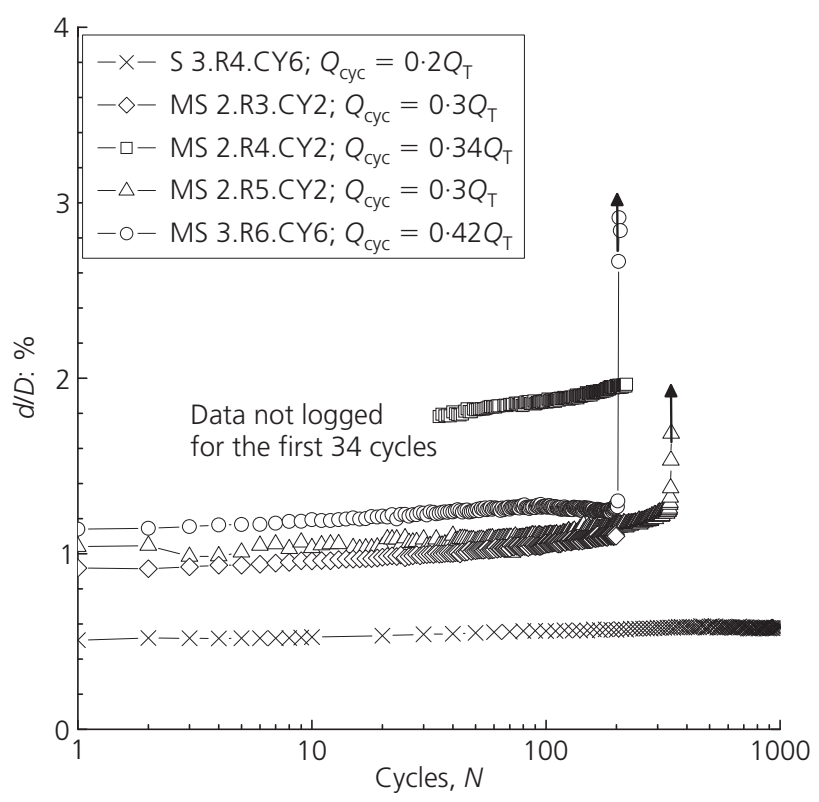

Figure 18. Transient cyclic displacements for stable and metastable tests 


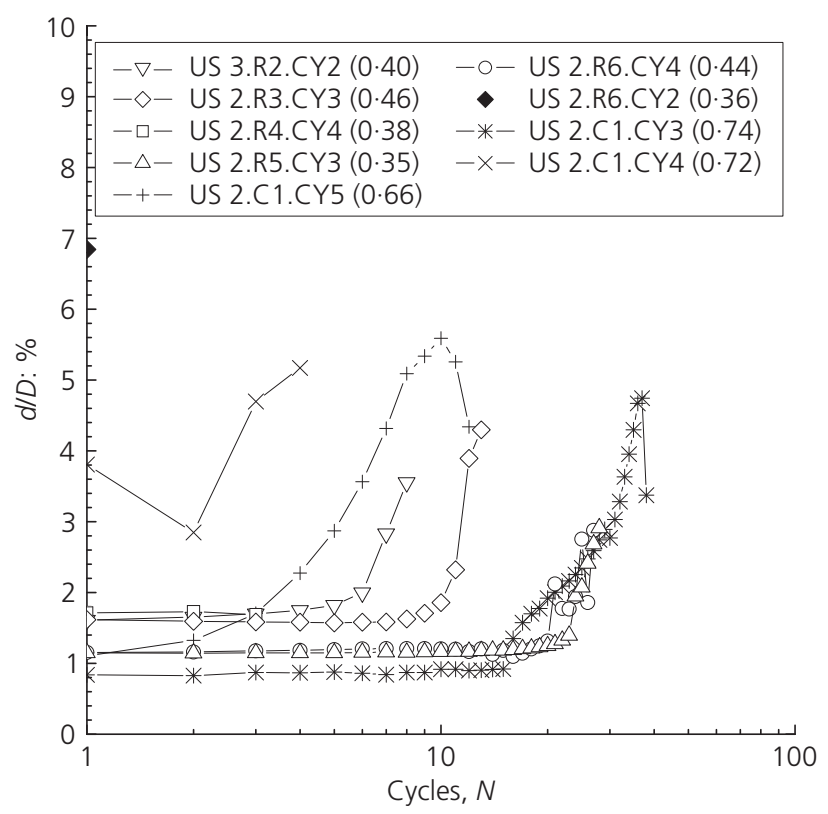

Figure 19. Transient cyclic displacements for unstable tests

cyclic tests on seven full-scale driven steel pipe-piles at a marine sand test site in Dunkerque, France. Reference static tension capacity tests were conducted between each cyclic experiment to enable the piles' capacity behaviour to be tracked and the results to be presented in the normalised cyclic stability interaction diagram outlined in earlier publications. The fundamental processes leading to the stable, metastable or unstable loading styles of response have been identified and discussed in earlier papers. This paper has analysed the load-displacement and stiffness responses of the only tests on steel tubular piles driven in silica sand of which the authors are aware. Six main conclusions are drawn, as follows.

(a) Load-displacement behaviour was highly non-linear, even at relatively low load levels, and depended critically on the applied cyclic load $Q_{\text {cyclic }}$.

(b) The normalised cyclic loading levels and proximity to potential cyclic failure are the key factors that affect the piles' cyclic displacement responses. A spread of cyclic stiffness and accumulated cyclic displacement trends applies to the stable, unstable and metastable loading styles of response defined in the piles' overall normalised interactive cyclic stability diagram.

(c) The piles' cyclic stiffnesses remained within $20 \%$ of those observed under initial static loading until cyclic failure was approached.

(d) The patterns of permanent cyclic strain accumulation were sensitive to both the mean and cyclic normalised loading levels.

(e) Whereas displacements accumulated rapidly over just a few cycles in the unstable zone, extended cycling in the stable zone led to minimal accumulated displacements and constant transient cyclic displacements. Metastable tests showed intermediate behaviour.

$(f)$ The axial cyclic load-displacement responses described in this paper have important implications for soil-structure interaction analyses of wind turbines, and add to those made regarding axial cyclic capacity reported by Atkins Consultants Ltd (2000) and Merritt et al. (2012).

\section{Acknowledgements}

The above research was funded by the EU (through the GOPAL project) and Health and Safety Executive (HSE) of the UK. The authors gratefully acknowledge the Port Autonome de Dunkerque for providing the test site, and the contributions from Mr Eric Parker of D'Appolonia (Italy). In situ testing was performed by the Building Research Establishment of Garston, UK, and Simecsol from Dunkerque, France. Laboratory soil testing was performed by former colleagues at Imperial College: Dr Fiona Chow, Dr Reiko Kuwano and Mr Tim Connolly. The field testing was conducted in conjunction with Precision Monitoring Control Ltd of Teesside, UK. The first author has been supported by the Commonwealth Scholarship Commission during the writing of this paper at Imperial College.

\section{REFERENCES}

Atkins Consultants Ltd (2000) Cyclic Degradation of Offshore Piles. Health and Safety Executive, London, UK, HSE Offshore Technology Report OTO 2000013.

Brucy F, Meunier J and Nauroy J (1991) Behaviour of pile plug in sandy soils during and after driving. Proceedings of the $23 \mathrm{rd}$ Offshore Technology Conference, Houston, TX, USA, OTC 6514, 145-154.

Chow FC (1997) Investigations into Displacement Pile Behaviour for Offshore Foundations. PhD thesis, University of London (Imperial College), UK.

Gavin K, Igoe D and Doherty P (2011) Piles for offshore wind turbines: a state-of-the-art review. Proceedings of the Institution of Civil Engineers - Geotechnical Engineering, 164(4): 245-256.

Jardine RJ (1991) The cyclic behaviour of large piles with special reference to offshore structures. In Cyclic Loading of Soils: From Theory to Design (O'Reilly MP and Brown SFD (eds)). Blackie, London, UK, pp. 174-248.

Jardine RJ (2008) Review of Technical Issues Relating to Foundations and Geotechnics for Offshore Installations in the UKCS, HSE Books, London, UK, Health and Safety Executive (HSE) Research Report RR 676.

Jardine RJ and Standing JR (2000) Pile Load Testing Performed for HSE Cyclic Loading Study at Dunkirk, France. Health and Safety Executive, London, UK, Offshore Technology Report OTO2000 007.

Jardine RJ and Standing JR (2012) Field axial cyclic loading experiments on piles driven sand. Soils and Foundations 52(4): 723-736.

Jardine RJ, Chow FC, Overy R and Standing JR (2005a) ICP 
Design Methods for Driven Piles in Sands and Clays.

Thomas Telford, London, UK.

Jardine RJ, Standing JR and Kovacevic N (2005b) Lessons learned from full-scale observations and the practical application of advanced testing and modelling. Keynote paper. Proceedings of the International Symposium on Deformation Characteristics of Geomaterials, Lyon. Balkema, Rotterdam, the Netherlands, vol. 2, pp. 201-245.

Jardine RJ, Standing JR and Chow FC (2006) Some observations of the effects of time on the capacity of piles driven in sand. Géotechnique 56(4): 227-244.

Jardine RJ, Puech A and Andersen KH (2012) Cyclic loading of offshore piles: potential effects and practical design. Proceedings of the 7th International Conference on Offshore Site Investigation and Geotechnics, London, UK.

Julio RMH (2009) Comportement des pieux et des groupes de pieux sous chargement latéral cyclique. Thèse de doctorat, Ecole Nationale des Ponts et Chaussées, Paris, France (in French).

Karlsrud K, Nadim F and Haugen T (1986) Piles in clay under cyclic axial loading: field tests and computational modelling. Proceedings of the 3rd International Conference on Numerical Methods in Offshore Piling, Nantes, France, pp. $165-190$.

Kuwano R (1999) The Stiffness and Yielding Anisotropy of Sand. $\mathrm{PhD}$ thesis, Imperial College London, London, UK.

Leblanc C, Houlsby GT and Byrne BW (2010) Response of stiff piles in sand to long-term cyclic lateral loading. Géotechnique 60(2): 79-90.
Merritt AS, Schroeder FC, Jardine RJ et al. (2012) Development of pile design methodology for an offshore wind farm in the North Sea. Proceedings of the 7th International Conference on Offshore Site Investigation and Geotechnics, London, UK, pp. 439-447.

Parker EJ, Jardine RJ, Standing JR and Xavier J (1999) Jet grouting to improve offshore pile capacity. Proceedings of the Offshore Technology Conference, Houston, TX, USA, OTC 10828, vol. 1, pp. 415 - 420.

Poulos HG (1988) Cyclic stability diagram for axially loaded piles. Journal of Geotechnical and Geoenvironmental Engineering 114(8): 877-895.

Puech A, Canou J, Bernardini C et al. (2012) Solcyp: a four-year JIP on the behaviour of piles under cyclic loading. Proceedings of the 7th International Conference on Offshore Site Investigation and Geotechnics, London, UK, pp. 263-270.

Seidel M (2007) Jacket substructures for the REpower 5M wind turbine. Proceedings of the European Offshore Wind Conference, Berlin, Germany. See http://www.marc-seidel.de/ papers/seidel_EOW_2007.pdf (accessed 12/12/2012).

Sommé J (1969) La plaine maritime. Annales, Société Geologique du Nord 89(1): 117-126 (in French).

Thomas S (1990) Geotechnical Investigation of UK Test Sites for the Foundations of Offshore Structures. Department of Energy, HMSO, London, UK, OTH Report 89294.

Tsuha CHC, Foray PY, Jardine RJ et al. (2012) Behaviour of displacement piles in sand under cyclic axial loading. Soils and Foundations 52(3): 393-410.

\section{WHAT DO YOU THINK?}

To discuss this paper, please email up to 500 words to the editor at journals@ice.org.uk. Your contribution will be forwarded to the author(s) for a reply and, if considered appropriate by the editorial panel, will be published as a discussion in a future issue of the journal.

Proceedings journals rely entirely on contributions sent in by civil engineering professionals, academics and students. Papers should be 2000-5000 words long (briefing papers should be 1000-2000 words long), with adequate illustrations and references. You can submit your paper online via www.icevirtuallibrary.com/content/journals, where you will also find detailed author guidelines. 